\title{
Green area loss in San Juan's inner-ring suburban neighborhoods: a multidisciplinary approach to analyzing green/gray area dynamics
}

\author{
Luis E. Ramos-Santiago ${ }^{1}$, Luis Villanueva-Cubero ${ }^{2}$, Luis E. Santiago-Acevedo ${ }^{3}$ and Yasha N. Rodriguez-Melendez $^{4}$
}

\begin{abstract}
The loss of green areas and vegetation in suburban neighborhoods poses short- and long-term consequences associated with environmental changes and socioeconomic decline that can propel such developments to an unsustainable state. We summarize an interdisciplinary investigation aimed at identifying the drivers of green area loss, green cover loss, and quantifying the impact on three inner-ring suburban neighborhoods located along the Rio Piedras watershed in San Juan, Puerto Rico. An inductive approach to social-ecological research was undertaken because it provides a flexible platform for interdisciplinary collaboration on this complex and dynamic subject. The three developments selected for the study were constructed in the mid-20th century under paradigms of modernity that included providing conditions for a better and more dignified way of living, among which green areas played a central role. The green area change analysis was undertaken first, by way of using building footprint growth as a proxy, which represents a minimal estimate of change, and transferring the information from aerial photographs, original development plans, construction drawings, and GIS maps to AutoCAD to quantify building footprint change for each neighborhood. The period of analysis started from the time of the construction of each development to the year 2010. The second estimation was performed using orthorectified infrared aerial imagery to quantify green cover in year 2008 and contrast that information with the conditions at the time the developments were constructed. Green-gray area dynamics were thus analyzed together with longitudinal socioeconomic data to help in the assessment of effects. The investigation revealed long-term socioeconomic declining trends in two of the neighborhoods, weak governance of the built environment, substantial increase in automobile ownership, and distinct physical-spatial characteristics as drivers behind the changes observed. The complexity and variety of exogenous and endogenous factors that have been identified in this study as affecting private and public inner-ring suburban green areas reveals dynamic and spatially differentiated concomitant processes and suggests that these are conditioned by the socioeconomic trajectories of each neighborhood and by larger metropolitan scale socioeconomic and technological trends. Lower income neighborhoods reflect a tendency for socioeconomic decline and greater loss of green areas and vegetation cover in time, thus suggesting policies geared toward adaptive governance. In contrast, the upper income neighborhood exhibits a more stable socioeconomic trajectory and less significant green area loss as well as increase in vegetation cover. Three hypotheses are posited for future sampling increments and testing. The findings and literature on urban economics and the decline of inner-ring suburbs in the U.S. suggest the need for policy geared to sustainable urban redevelopment as a strategy for adaptive governance. The competing needs for land by higher density uses and by green areas in sustainable redevelopment initiatives requires a trade-off analysis in which a thorough account of costs and benefits is warranted. As such, sound data as that presented in this paper will aid urban ecological design in the process of achieving sustainable and environmentally sound land-use adaptations that seek to recuperate green areas' environmental services in urban and suburban contexts.
\end{abstract}

Key Words: green area loss; inner-ring suburbs; land-use science; neighborhood decline; Puerto Rico; social-ecological; sustainability; urban dynamics; urban planning

\section{INTRODUCTION}

Urban and suburban residential green areas are considered beneficial for the natural environment and for society's well-being. They provide significant health, economic, and ecological benefits (James et al. 2009). As humanity becomes more urbanized this limited resource becomes the first scenario where future generations experience nature. It also becomes more threatened in the presence of other competing urban land uses. As such, the loss is problematic. This exploratory case study is geared to the quantification of changes in green area loss/gain and green cover loss/gain in three inner-ring suburbs of San Juan. For purposes of this paper green area refers to unbuilt surfaces and green cover refers to surfaces with vegetation including those between structures and canopy cover. We aim to identify and understand the drivers and mechanisms associated to green-grey area change and assess environmental consequences. An inductive approach to social-ecological research was undertaken because it provides a flexible platform for interdisciplinary collaboration on this complex and dynamic subject.

A consensus among the selected literature is that urban and suburban green areas are beneficial for the natural environment and for society's well-being. They are an integral part of cities that provide a range of services to both people and the wildlife living in urban areas (James et al. 2009). They provide significant social, health, economic, and ecological benefits (Tratalos et al. 2007, Di Giulio et al. 2009, James et al. 2009, Pickett et al. 2011, Ward Thompson et al. 2012). Additionally, urban and suburban green areas have the potential for mitigating climate change, harboring biodiversity, and improving urban quality of life. As such, they are a key element for advancing sustainability. Furthermore, from the urban planning-design perspectives, suburban green areas constitute an indispensable functional and aesthetic element of the suburban landscape and their continuous detriment and/or loss are considered problematic (Appendix 1).

${ }^{1}$ The Florida State University, Department of Urban \& Regional Planning, ${ }^{2}$ University of Puerto Rico, Department of Natural Sciences, ${ }^{3}$ University of Puerto Rico, Graduate School of Planning, ${ }^{4}$ Centro de Estudios Avanzados y del Caribe 
Table 1. Secondary data sources.

\begin{tabular}{|c|c|c|c|}
\hline Vector & Source & Agency & Information Type \\
\hline Socioeconomic & $\begin{array}{l}\text { U.S. Censuses 1960, 1970, 1980, 1990, 2000, } \\
2010\end{array}$ & $\begin{array}{l}\text { U.S. Census Bureau, } \\
\text { University of Puerto Rico- } \\
\text { Centro de Datos Censales de } \\
\text { Puerto Rico (Biblioteca } \\
\text { Lazaro) }\end{array}$ & Socioeconomic, housing characteristics \\
\hline Physical-spatial & $\begin{array}{l}\text { Archivo General de Puerto Rico, Centro de } \\
\text { Recaudación de Impuestos Municipales, } \\
\text { Departamento de Transportación y Obras } \\
\text { Publicas, local architecture and historic } \\
\text { urbanism literature, Rockefeller Archive } \\
\text { Center, Archivo de Arquitectura y } \\
\text { Construcción de la Universidad de Puerto } \\
\text { Rico-AACUPR, Biblioteca Digital } \\
\text { Puertorriqueña-Colección el Mundo, } \\
\text { Colección Piñero }\end{array}$ & $\begin{array}{l}\text { Commonwealth of Puerto } \\
\text { Rico, Rockefeller Archive } \\
\text { Center, University of Puerto } \\
\text { Rico, Universidad } \\
\text { Metroplitana - UMET }\end{array}$ & $\begin{array}{l}\text { Original plot plans and architectural } \\
\text { plans, digitalized plot plans and } \\
\text { structure footprint shapefiles, } \\
\text { orthorectified infrared aerial images, } \\
\text { street level historical photographs, } \\
\text { scaled architectural plans, interviews to } \\
\text { residents, and historical notes }\end{array}$ \\
\hline Cultural Arrangements & Legal deeds, Reglamento de Zonificación & $\begin{array}{l}\text { Departamento de Justicia de } \\
\text { Puerto Rico-Registro de la } \\
\text { Propiedad, Junta de } \\
\text { Planificación de Puerto Rico, } \\
\text { Municipio Autónomo de San } \\
\text { Juan }\end{array}$ & $\begin{array}{l}\text { Zoning regulations, private development } \\
\text { covenants, historical data of } \\
\text { developments, property inscription } \\
\text { deeds }\end{array}$ \\
\hline
\end{tabular}

Studies geared to quantify and explain long-term changes in suburban private and public green areas are scarce. This aspect of the social-ecological system dynamics is significant because of the contemporary dominant proportion of suburban landscapes in urban agglomerations within industrialized countries (Di Giulio 2009). Nonetheless, a research agenda on urban green areas that recognizes this gap can be found in some of the existent social-ecological literature (James et al. 2009, Picket et al. 2011) where emphasis is placed in multidisciplinary, interdisciplinary, and transdisciplinary approaches to social-ecological and urban green area studies. Also, multiscalar and long-term studies are espoused so as to improve the understanding of social-ecological interactions in time.

Pickett et al. (2011) argue for a social-ecological approach through the lens of land change science and makes a call for the integration of urban design, planning, and ecology so as to advance a more sustainable social-ecological system through urban ecological design. As noted by Aspinall (2006:1):

\section{Land change science inclusively defined, and subject material includes, but is not limited to, studies of the nature of land use and land cover, their changes over space and time, and the social, economic, cultural, political, decision, environmental, and ecological processes that produce these patterns and changes.}

After rapid growth during the mid-20century, mostly in a suburban format, some of the first suburbs of San Juan are evincing a noticeable loss of public and private green areas, declining socioeconomic trends, and physical deterioration (Ramos 2008). As such, the loss of significant portions of this seminatural resource could have negative effects and constitute a significant perturbation on the social-ecological system (Appendix 2).
Further, it is important to frame this observation within current global and local demographic trends toward increased urbanization. As stated by Kinzig et al. (2005:10-12),

$[N]$ early all of the human population growth in the next 30 years is expected to be in urban areas. As the world becomes increasingly urban, the number of global residents will have their primary interactions with nature in an urban setting; this means that the daily interactions with nature for most people will come from their yards, streets, neighborhood parks, and urban forests. Our collective conservation ethic and philosophies of proper human-environment relationships will increasingly spring from these urban experiences. Lack of access to urban (and suburban) nature may have implications for how those ethics and relationships develop in the future.

\section{METHODS}

Based on the land change science approach and Boyden's Human Society-Biosphere Interplay Framework (1992) we identified and documented several long-term cultural arrangements, physicalspatial characteristics, and socioeconomic variables for the three inner-ring suburban neighborhoods within a time span of approximately 50 years or more, depending on the year of construction for each development. This three-vector structure for data collection, variable identification, and analysis represents a generalized scheme in many land-change case studies (Aspinall and Hill 2008), social-ecological and urban planning studies. Data for the three vectors is available in both official government institutions and private/public academic sources (see Table 1). Existent spatial analysis technologies, such as AutoCAD and ArcGIS together with on-site surveys allowed for spatial harddata generation. 


\section{Neighborhoods subject to study}

The present study used the neighborhood as the basic geographic unit for comparative analysis because of its identifiable physical limits, shared physical and urban-ecological history, and its propensity for harboring interpersonal interactions (i.e., sustained interpersonal relationships in communities, as explained by Lozano 1990). As such, it is considered a dual entity in tune with the social-ecological approach, containing physical as well as social attributes.

The three selected suburbs are located within the sampling area of San Juan ULTRA-Exploratory project, set within the Río Piedras River Watershed in the San Juan Metropolitan area (Appendix 3). The selection of neighborhoods was based on the following four criteria: (1) location within preselected larger sites as defined in the San Juan ULTRA-Exploratory multidisciplinary project; (2) consisted of uniform planned developments; (3) existence of U.S. census tract boundary that closely matches or contains the original physical boundaries of the residential neighborhoods; and (4) had distinct architectural, typological, and social-economic characteristics. The first criterion reflects the desirability of a multidisciplinary approach to social-ecological studies within a common geographic sample so that the several research initiatives within the San Juan ULTRA-Exploratory project can feed each other data, analysis, and create the possibility of convergence. The second criterion responds to the desire to evaluate similar-age and homogeneous urban developments through time. The third criterion responds to a geographic matching requirement between social-economic characteristics and physical characteristics (green-gray area) for the corresponding long-term social-ecological and land-change science analysis. The fourth refers to previous research by other scientists that link neighborhood social-economic and physicalspatial characteristics to specific green area environmental services and characteristics.

Given the aforementioned criteria, three inner-ring suburban neighborhoods were selected for this study. In this research we use the definition for inner-ring suburbs provided by Lee (2005:17): "post-WWII suburbs that were constructed between 1950 and 1969 and for which the primary mode of transportation access has been the automobile." The neighborhoods are the following (Appendix 3; U.S. Census Bureau 2010): (1) Puerto Nuevo (U.S. Census Tract 70.04, 2010), (2) Caparra Terrace (U. S. Census Tract $83.00,2010$ ), and (3) University Gardens (U.S. Census Tract 86.01, 2010).

\section{Brief historical review of selected neighborhoods}

Puerto Nuevo was the first mass-produced suburban neighborhood in San Juan geared to a growing working-class market and returning war veterans (Sepulveda 2003). Its construction started in 1948 and was designed for 7000 one-story detached single-family reinforced concrete houses and to accommodate 50,000 residents (El Mundo 1948a). It consists of 11 sections, each containing an average of 550 housing units, with an average lot size of $250 \mathrm{~m}^{2}$ and a $58 \mathrm{~m}^{2}$ original structure's footprint. It was, in part, based on Clarence Perry's "neighborhood-unit" model but also shares with Clarence Stein's model its aggregate-neighborhood structure, institutional, and an overall district scale layout as well as programming of public functions (Lang 1987, Ramos 2012). At the time of construction it was considered the largest suburban residential development in the world (El Mundo 1948b). The design consisted of two bedrooms, one bathroom, shared living-dining space, and a small balcony. There was no carport structure and bus transit originally operated as the main mode of transportation.

The construction of Caparra Terrace, by the same parent company of Puerto Nuevo, started almost a decade later (1956). It was geared toward the same working-class market. The selected Census Tract (83.00) consists of identical one-story reinforced concrete structures, but in a duplex format, i.e., two paired housing units share a common median wall. This sector contained neighborhood-scaled commercial lots located at key intersections. It also accommodated an elementary school within its boundaries, in tune with Perry's neighborhood model. The average residential lot size is $550 \mathrm{~m}^{2}$ and carport structures are absent. The original residential structure footprint for the duplex model (two-housing units) was $150 \mathrm{~m}^{2}$ (75 each).

University Gardens is an upper middle-class, inner-ring suburban development whose construction started in the late 1950s. It was developed in two phases and consists mostly of one-story singlefamily detached housing, also built in reinforced concrete. An area to accommodate a school was provided, as well as a park that is now a baseball field. A small local commercial block is located near the neighborhood's center and distant to peripheral arterial avenues. In contrast to the two previous neighborhoods, the University Gardens project contained eight different detached residential models of different sizes and configurations. However, all the models share a purposeful tropical design that seeks to integrate exterior green areas with interior living spaces, promoting interaction, cross-ventilation, and use of yards. The average residential lot size is $500 \mathrm{~m}^{2}$ and all original residential structures included an attached carport.

\section{Boundaries}

For each U.S. Census Tract studied there is a neighborhood study area boundary, and a net residential area boundary. The neighborhood study area discards large tracts of land, such as military bases and waste facilities, while keeping neighborhoodscale public and institutional parcels such as parks and schools. The net residential area, on the other hand only considers residential parcels within a U.S. Census Tract for which original single-family detached residential structures were identified and whose original footprint was reproduced in digital (AutoCAD) format.

\section{Physical-spatial characteristics: green area and green cover} Our research on private and public suburban residential green areas explored two methods for quantifying green/gray area dynamics. Method \#1 sought to estimate open green area loss or gain within a 50 -year time span or more, depending on the year of construction for each neighborhood, i.e., estimating the loss of unbuilt surface. Method \#2 sought to estimate green cover loss or gain for the same time period, i.e., estimating the loss of vegetation. Further we estimated street planting-strip area loss for each neighborhood.

Method \#1 estimated green area loss by using building footprint growth as a proxy, which represents a minimal estimate of change. It quantified unbuilt surface, lost or gained, from the time each neighborhood was constructed up to 2008 , which is the year of 
the most up-to-date municipal cadastral map. The process begins by documenting original architectural plans and neighborhood layouts for each development in public and private archival records. The architectural layout of all residential structure models were redrawn to scale in digital media using AutoCAD 2011 software. Each housing structure was placed in its corresponding residential parcel in digital format. The digital parcel base map was provided by the Puerto Rico Municipal Tax Collection Agency (CRIM - Centro de Recaudación de Impuestos Municipales) in a Geographic Information System (GIS) format (shapefiles). This information was developed using $0.3-\mathrm{m}$ resolution orthorectified aerial imagery. The base parcel information layer was then converted to AutoCAD format and used as base map in AutoCAD files for the placement of residential structure footprints.

Using original land-use plans, plot plans, and historic and recent aerial and street-level photographs, an original green/gray development scenario for each neighborhood was recreated in a two-dimensional digital form. The total residential footprint area was quantified for each neighborhood using AutoCAD standard AREA command. Vacant lots and structures that were not matched with original documented architectural layouts or that were built at a later date were not considered.

A second scenario was prepared for each neighborhood in AutoCAD for the year 2008; the Municipal Tax Collection Agency provided an up to date building footprint layer in GIS format, which was imported to the AutoCAD file. The original residential footprint area was subtracted from the updated year 2008 residential footprint area. The difference in footprint area represents footprint growth as well as diminishment of yard areas; as such it serves as a proxy for loss of open green area. This would serve as a minimum threshold because other nonroofed paved surfaces, with the exception of swimming pools, are not accounted for in this methodology. Nevertheless, it provides land-cover general trends and helps identify differential green-gray area ratios among the three distinct neighborhoods.

Method \#2 was similar in process to the first, but aimed to quantify green cover loss or gain rather than referring to built and unbuilt changes. Green cover calculations for each neighborhood were performed with year 2010 orthorectified infrared aerial imagery provided by the Department of Transportation and Public Works (DTOP) over two distinct geographical boundaries. The first boundary category "a" was based on the neighborhood net residential area concept. This aimed to quantify green cover over all sampled private residential areas used in Method \#1. The second boundary category "b" was based on the neighborhood study area, which aimed to quantify green cover over the entire neighborhood limits and proportion it to three land-use classifications used in this research. ArcGIS software was used in the analysis of these images, which have a resolution of 0.3 meters. In this Method \#2 green area calculations from the original scenarios recreated in Method \#1 were assumed to be equivalent to the green cover calculations for the year of construction of each neighborhood because all original trees were downed during site preparation and grading operations completely erased other types of green cover in anticipation of the construction of new residential housing structures and neighborhood infrastructure. As such, the change in green cover gain or loss was calculated by subtracting the original open private yard areas calculated in Method \#1 from the year 2010 green cover calculation. Each of these two measures, green cover loss and green area loss, help in the understanding of green-gray area dynamics and could help in the assessment of distinct environmental services that might be affected by changes in the quantity of green area and/or green cover, such as hydrological cycles and storm run-off calculations, carbon sequestration assessment, biomass calculation, flora and fauna studies, microclimate analysis, among others.

Street planting strips are also a fundamental aesthetic element of the suburban streetscape and contribute to the hydrological permeability of urban landscapes. They provide area for trees and ornamental plants and grass. Despite the fact that planting strips in suburban neighborhood streets are located for the most part in public property (street right-of-way), in practice they are under the direct influence of residents, usually those closest to the strips. As such, planting strip areas are considered part of the private green area assessment and are quantified for purposes of this exploratory case study.

The original planting strip area was estimated by multiplying the length times the width for each development. These were verified on site for all the distinct residential developments within the neighborhoods. The estimation of street planting strip loss consists in subtracting present planting strip area from the original planting strip area. The present planting strip area was estimated using year 2010 infrared orthorectified aerial imagery, imported to AutoCAD software. The total length of the remaining planting strip along local streets was registered as line segment; subtotal length estimation for each development was then multiplied by the typical planting strip width.

\section{EVALUATION OF RESULTS}

\section{Cultural arrangements}

The investigation of cultural arrangements for the selected neighborhoods revealed that although they were designed with restrictive covenants, these have not served to thwart overdevelopment and taxing of resources. Interestingly, all neighborhoods were planned and developed according to the then current regulations and processes established by the Puerto Rico Planning Board, which had been established in 1942. Zoning code districts for residential, commercial, and public uses were employed as well as private arrangements. Among these we identified provisions for both private and public green areas, communal facilities within a car-dependent modern suburban setting, defined restrictions of use, and specified setback requirements. A diversity of restrictive covenants that directly or indirectly provided an additional layer for green area protection, building footprint limits, setback requirements, and height and use limitations were also identified in each neighborhood legal deeds. These public regulatory instruments and private arrangements were geared to provide and conserve green areas and maintain the general character and values in each neighborhood. These, however, have not been effective and, it could be argued, abandoned (Rodríguez-Meléndez 2012).

\section{Physical-spatial profile}

After over 50 years significant green area loss has occurred in all three neighborhood private residential areas and public areas as well. The lower-income communities of Puerto Nuevo and 
Caparra Terrace have a higher rate of loss compared to University Gardens. The rates of loss are $60 \%, 55 \%$, and $36.5 \%$, respectively and represent a collective loss of 30.28 hectares. Because existing nonroofed paved surfaces were not quantified, actual green area loss in all three neighborhoods is larger (Appendices 4, 5, 6).

In the same time period, Puerto Nuevo and Caparra Terrace also registered a loss of green cover. University Gardens had an increment in green cover despite experiencing a residential footprint increase of $63 \%$. Most of the present day vegetation in all three neighborhoods occurs in public/institutional lands, e.g., schools grounds, required water body setbacks, street planting strips, parks, etc., and there is a visible loss of vegetation (Appendix 7).

Increase in total housing units occurred in all three neighborhoods. Increases in net and gross residential density and footprint area, with Puerto Nuevo and Caparra Terrace exhibiting the larger figures, occurred as well (Fig. 1). The percentage of housing units in multifamily structures also reflects rising trends (Fig. 2), with particular typological differences favoring multistory condominium properties in University Gardens. Further, all neighborhoods register commercial land-use conversions in detriment of residential land-use, particularly along peripheral arterial avenues and local collector streets, with more of such impact in Puerto Nuevo and Caparra Terrace.

Fig. 1. Net residential density (housing units/hectare).

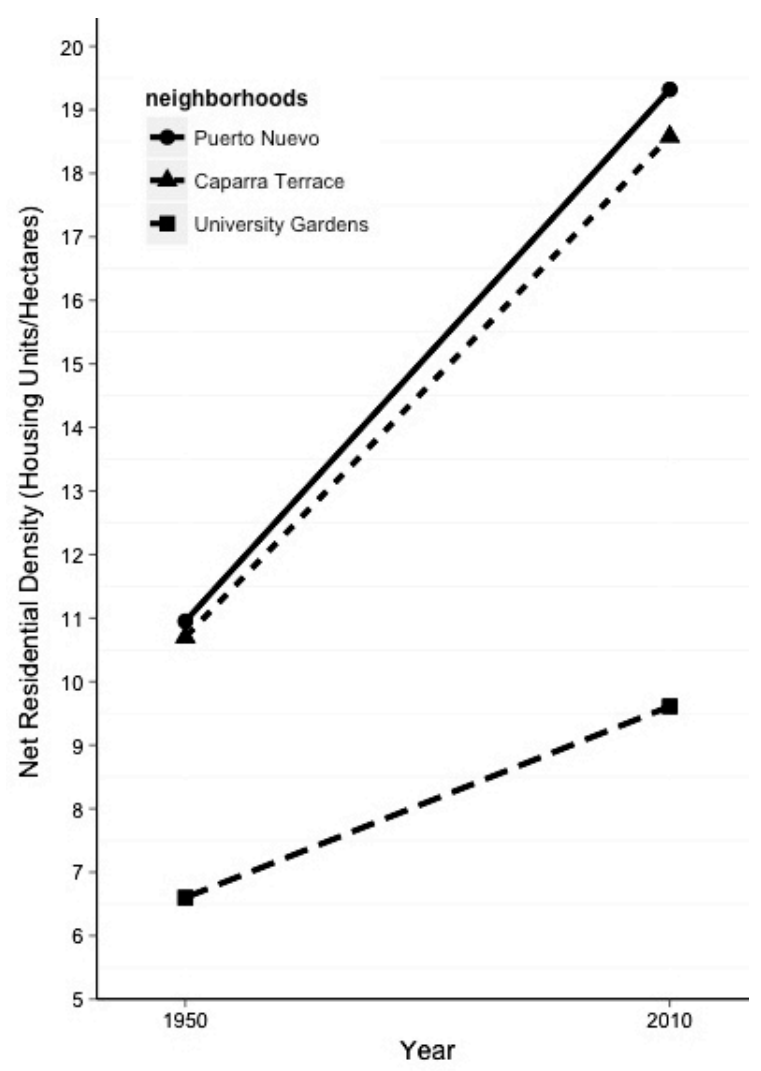

Fig. 2. Percent multifamily structure.

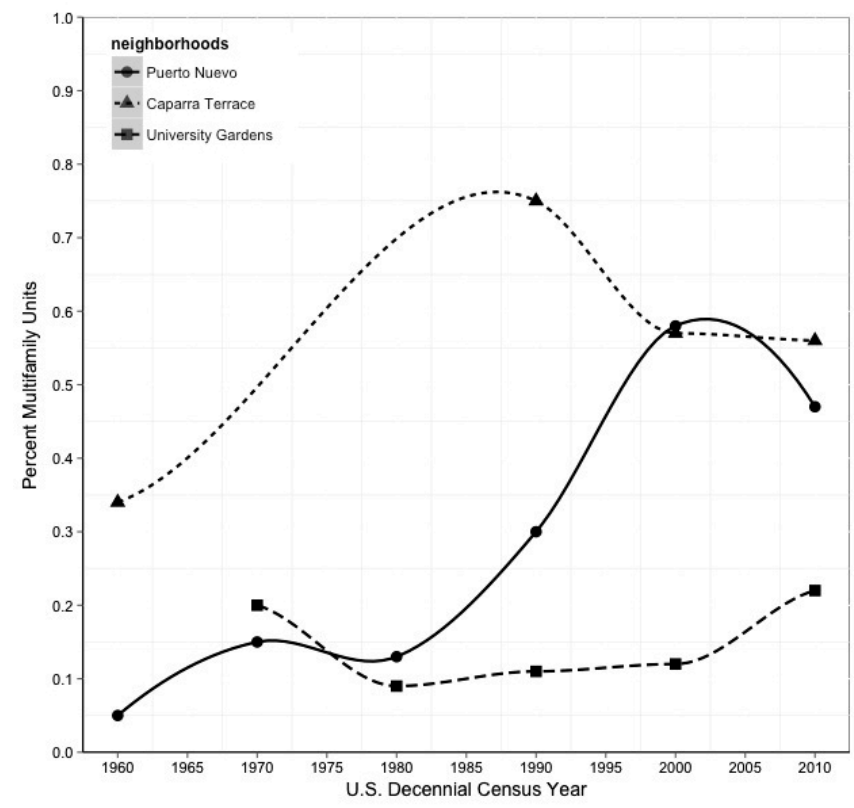

Average residential lot size in Puerto Nuevo and Caparra Terrace is approximately $50 \%$ that for University Gardens $\left(250 \mathrm{~m}^{2}\right.$ vs. $500 \mathrm{~m}^{2}$ ). Also, Puerto Nuevo exhibits significantly narrower roadway widths when compared to University Gardens', $4.88 \mathrm{~m}$ vs. $8.07 \mathrm{~m}$, respectively.

\section{Socioeconomic profile}

The socioeconomic data that characterizes Puerto Nuevo and Caparra Terrace differs from that of University Gardens. Median family income, percentage of family poverty, median structure values, and unemployment figures place Puerto Nuevo and Caparra Terrace in a lower socioeconomic level when compared with University Gardens and San Juan City. In contrast, socioeconomic figures for University Gardens reflect median values above those of Puerto Nuevo and Caparra Terrace and above the median for the City of San Juan, despite exhibiting slight declining trends in some variables (Figs. 3 to 6).

The socioeconomic trends for both Puerto Nuevo and Caparra Terrace point toward a declining process that can be described as an ongoing intermediate stage of neighborhood decline. An increment of families under the poverty threshold, decreasing housing structure values relative to the median housing values in San Juan, an increase in the percentage of unemployed residents, and increase in the percentage of housing rentals and multifamily structures are some of the trends indicative of neighborhood decline process (Lowry 1960, Goodall 1972, Leven et al. 1976, Little 1977, Downs 1981, Metzger 2000, Hanlon 2009; Figs. 2, 7). 
Fig. 3. Median family income.

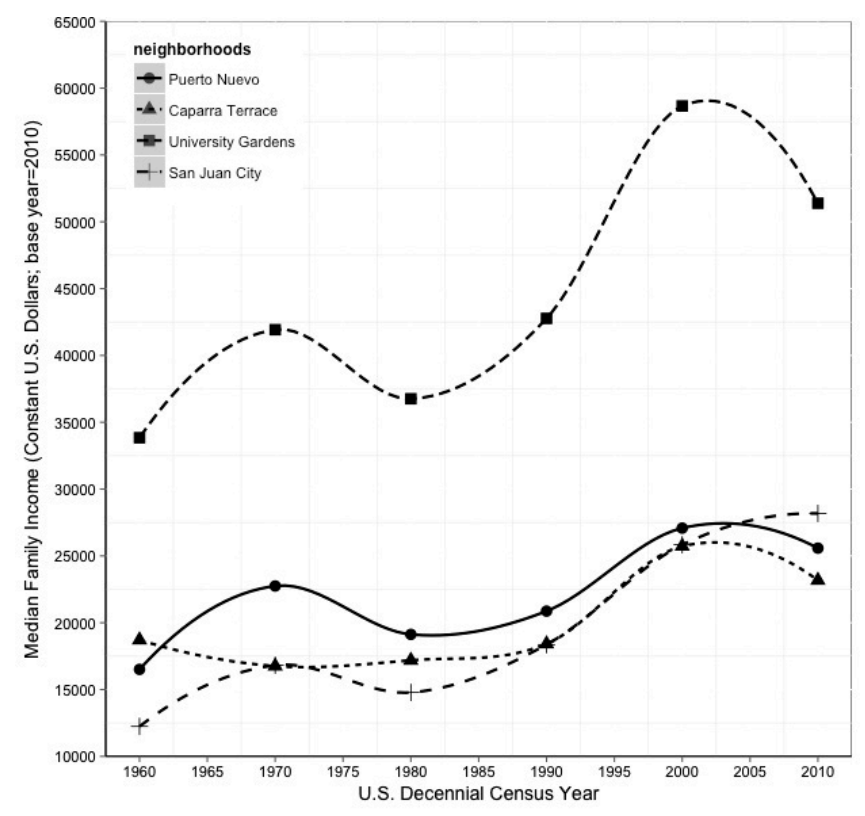

Fig. 4. Percent families under poverty threshold.

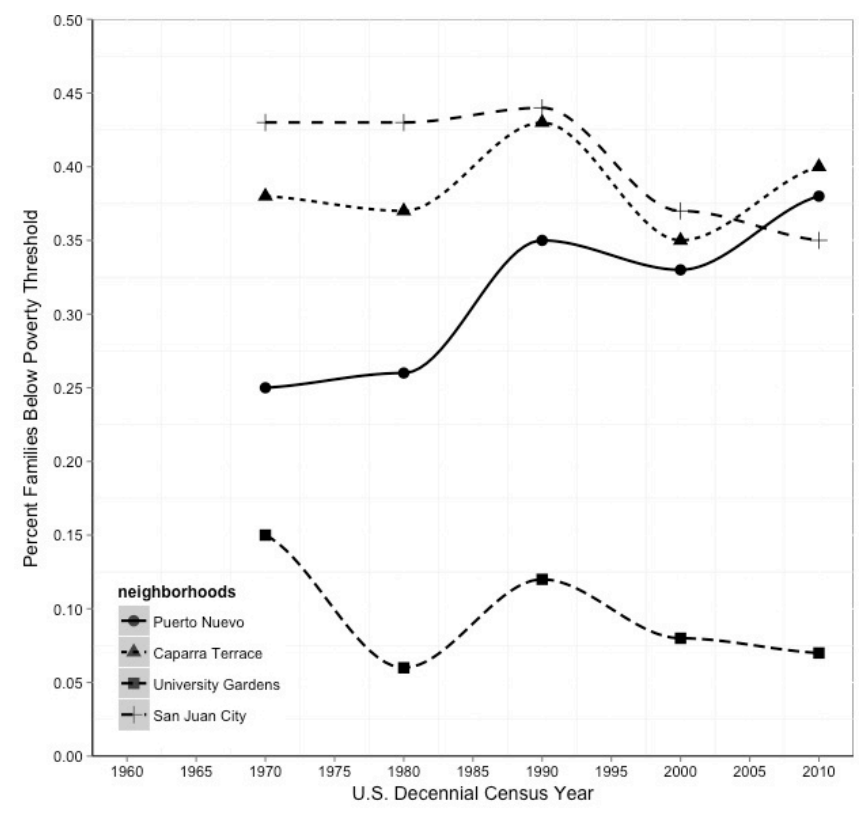

Fig. 5. Percent families with rents above $30 \%$ of income.

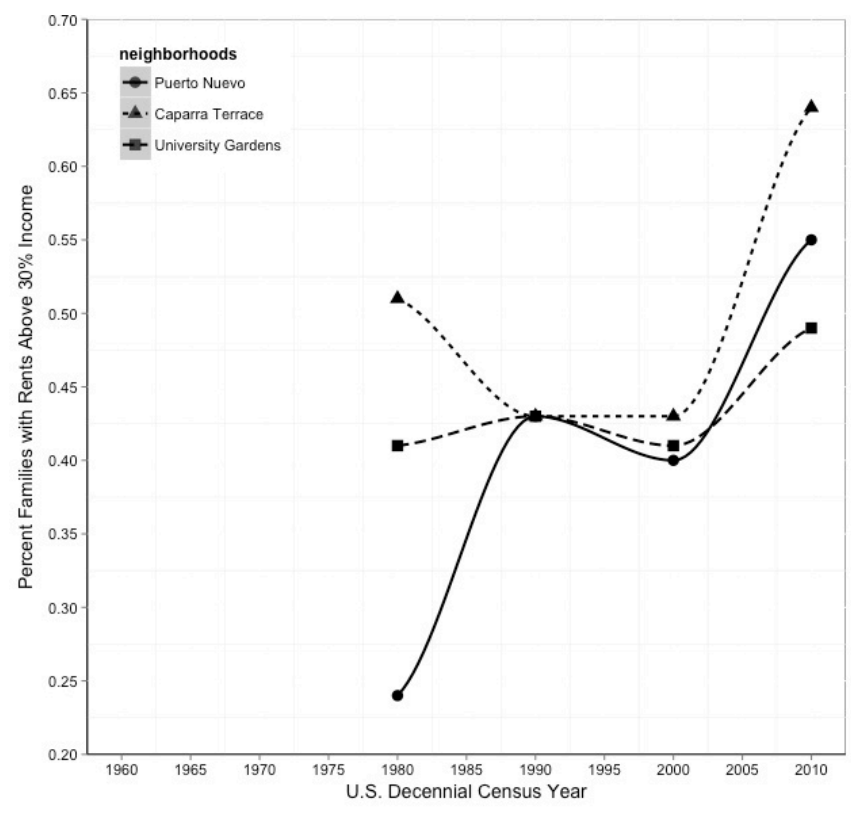

Fig. 6. Median structure value (U.S. dollars; base year = 2010).

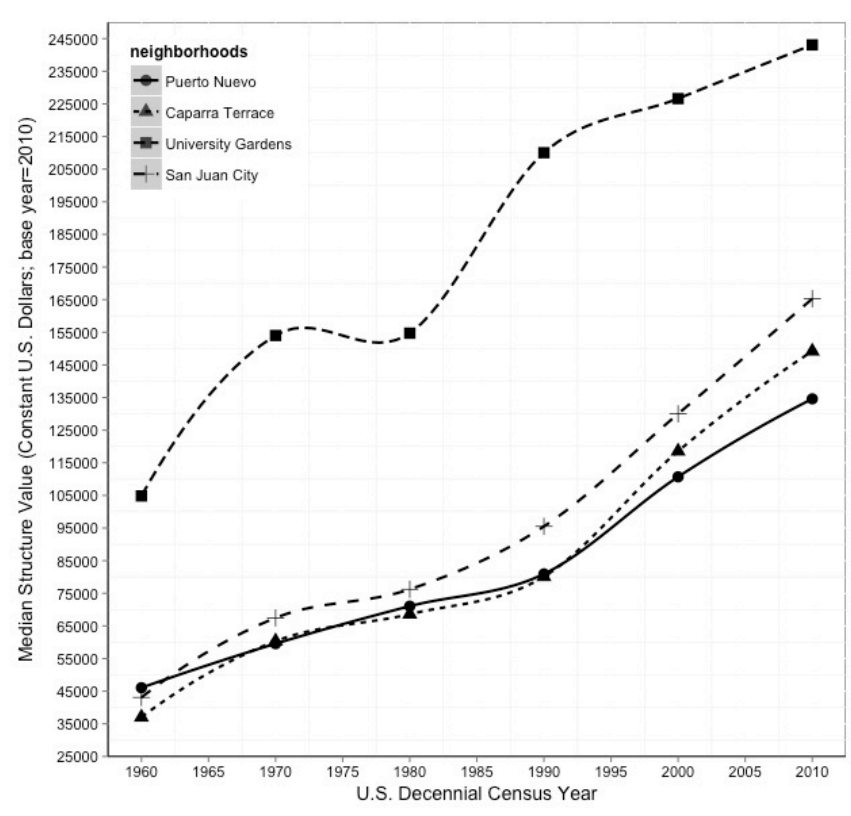


Fig. 7. Percent of housing units as rentals.

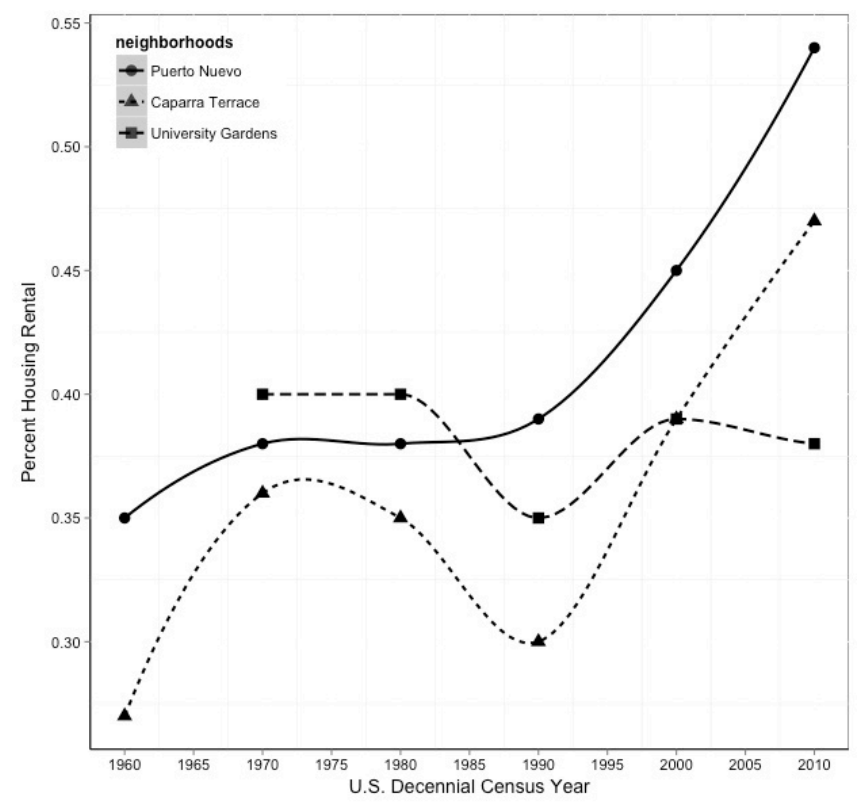

Population loss has occurred in all three neighborhoods despite an increase in the number of housing units (Fig. 8). Puerto Nuevo reports a 32\% population loss between 1960 and 2010; Caparra Terrace reports a $44 \%$ population loss in the same time period; and University Gardens had a $29 \%$ population loss between the years 1970 and 2010. For the same time period San Juan lost 11\% of its population.

Fig. 8. Population.

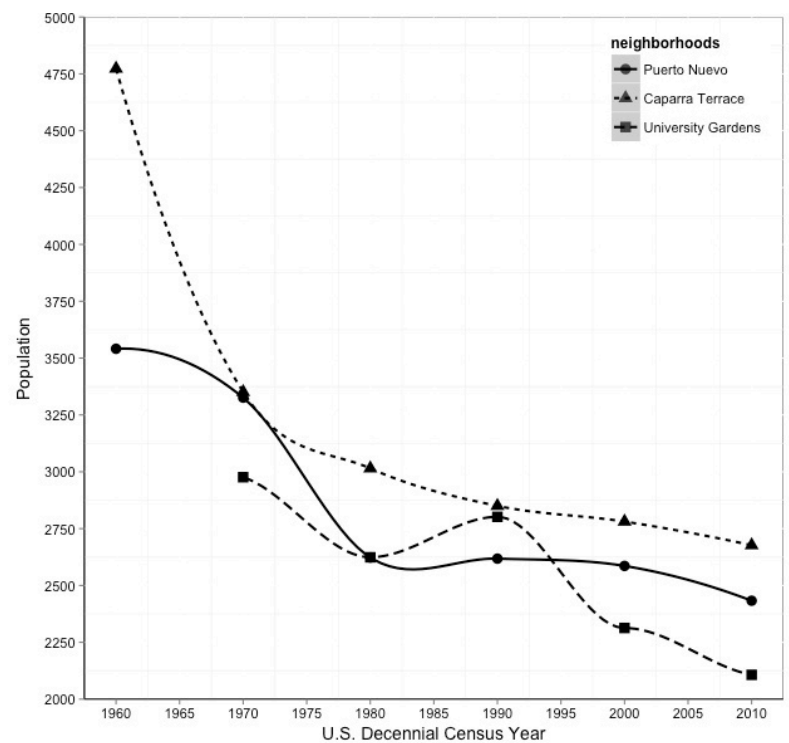

The apparent contradiction between population loss and increases in housing units and density is explained by two concurrent trends. First, the average population per housing unit has decreased steadily since the 1960s from an average of 4.77 people per housing unit to an average of 2.65 in year 2010 (see Fig. 9). That is, there are more housing units but less people occupying them. Second, the reported increase in residential density despite absolute population loss is explained by the fact that a substantial number of residential structures and lots along the neighborhoods' peripheral arterial avenues have been converted exclusively to commercial uses. As a result, the reported increase in housing units took place in a reduced number of residential lots at the core of each neighborhood. These trends have rendered an increase in housing units and rentals, a more dense and crowded landscape within the lower income suburban communities. This is reflected in higher net residential area density rates, which excludes the lots converted to exclusive commercial uses.

Fig. 9. Population per housing unit.

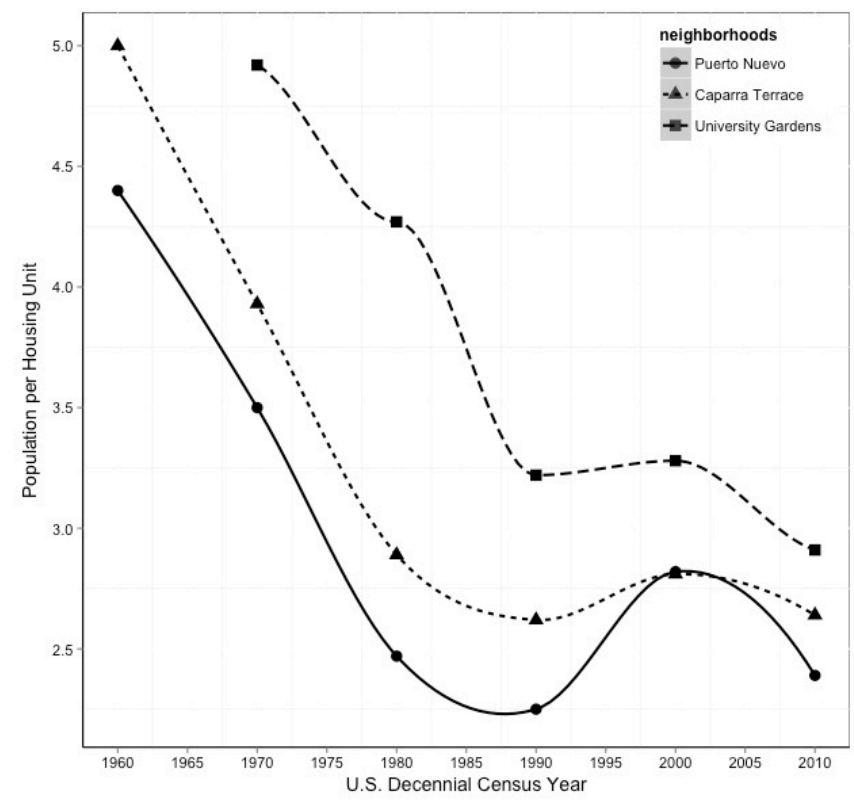

Another significant trend to consider because it directly affects green areas is the substantial increase in automobile ownership, doubling in the past 50 or more years for Caparra Terrace, tripling for Puerto Nuevo, and slightly declining for University Gardens (Fig. 10). Significant loss in planting strips and yard green areas is visible and responds, in part, to use of such surfaces for parking of automobiles (Appendix 7). As such, the original suburban landscape in both low-income communities has been completely transformed. 
Fig. 10. Automobile ownership.

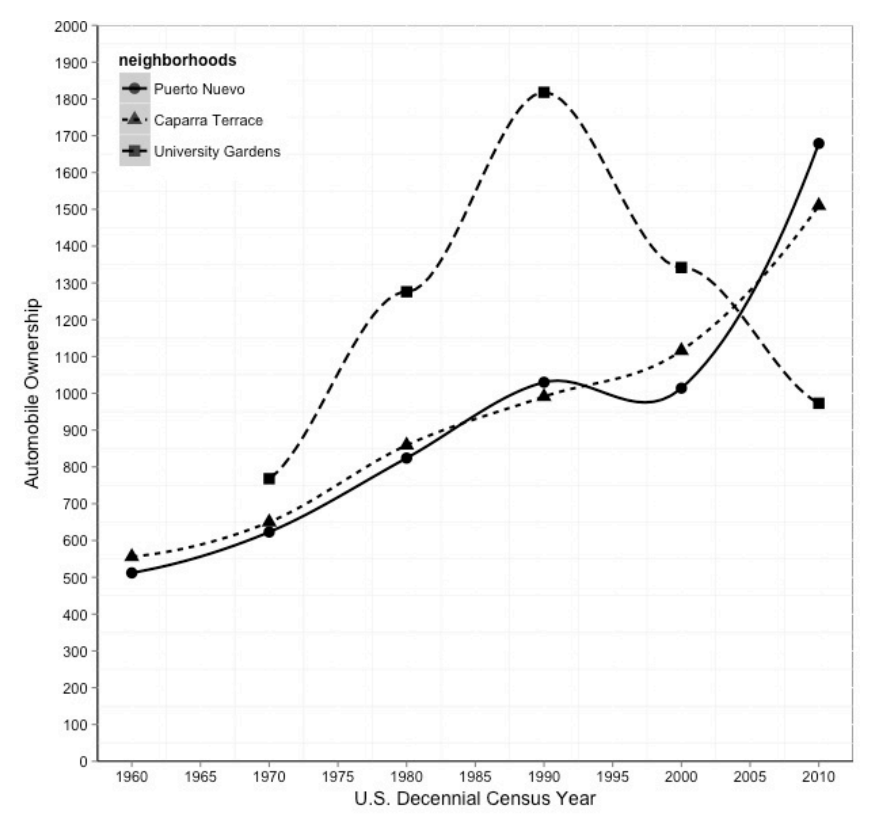

\section{DISCUSSION}

Green area loss has occurred in the inner-ring suburban neighborhoods of Puerto Nuevo, Caparra Terrace, and University Gardens at different rates and magnitudes. The two lower income neighborhoods of Puerto Nuevo and Caparra Terrace, which appear to be undergoing an intermediate stage of neighborhood life cycle, exhibit the highest rates of unbuilt surface loss and vegetation (ground and canopy) loss. In contrast, University Gardens, which was originally geared to middle- and upper-class households, exhibits less public and private green area loss, registers an increase in green cover, and maintains its general suburban character in the same, more than 50-year period. Most front yards, side yards, and street planting strips have been conserved (Appendices 3 to 6).

Green cover loss has also taken place in Puerto Nuevo and Caparra Terrace. It is possible that a relationship between their deteriorating socioeconomic characteristics, the institutional weak governance of the built environment in which they are set, and certain physical-spatial characteristics may explain their declining environmental trajectories as manifest in higher rates of green area and green cover loss.

We contend that a process of neighborhood decay is taking place in these two lower income neighborhoods. This phenomena is in part responsible for the higher rates of green area and green cover losses because it propels alterations and expansions to existing residential structures in accommodating new lower income housing demands (Lowry 1960, Goodall 1972, Leven et al. 1976, Little 1977, Downs 1981, Metzger 2000, Hanlon 2009).

Neighborhoods as a whole, like individual buildings, exhibit a cyclical pattern of change (Goodall 1972). After a period of relative stability, this pattern usually results in a lack of maintenance, abandonment, and the eventual demolition of a structure. In the case of neighborhoods the end result would be urban blight (Goodall 1972, Smith 1979, Metzger 2000). Several models with regard to neighborhood change, urban decline, and/ or decay have been developed and share a close relationship with the urban ecology perspective on neighborhood change prompted by deterioration. These can be grouped into three categories (Harrell and Geuvis 1994): (1) neighborhood life cycle (Goodall 1972, Smith 1979, Downs 1981); (2) arbitrage (Leven et al. 1976, Little 1977, Schwab 1987); (3) structure and composition (Leven et al. 1976, Little 1977).

The neighborhood life cycle model emphasizes housing stock depreciation as the fundamental cause of neighborhood change (Harrell and Geuvis 1994): as deterioration of structures takes place their value declines, this reflects in rent levels; as rent levels drop, property owners disinvest resulting in further deterioration; prices and rents decreases induce the incoming of lower income residents for whom prices and rent are affordable; because the housing stock in these neighborhoods is homogeneous, and on average have deteriorated at the same rate, residents' socioeconomic statuses are homogeneous as well. Hoover and Vernon (1959) further develop and refine this model by incorporating changes in the composition of residential structures. That is, conversion of single-family buildings to multifamily use increases the densities of urban neighborhoods without changing stock composition (Harrell and Geuvis 1994).

The arbitrage model places primary weight on the social, racial, and/or ethnic preferences of existing neighborhood residents and potential immigrants and recognizes the importance of the bundle of housing services (Harrell and Geuvis 1994). This bundle consists of more than physical characteristics of the stock and incorporates location features associated with proximity and geography. As explained by Harrell and Geuvis (1994), these social, racial, and/or ethnic preferences can work in two directions. First, ethnic solidarities can limit the housing market to those for whom ethnic composition holds primary place in their home purchase decision. In the second possible direction of the arbitrage model ethnic and social class preferences result in both white flight, based on shifting or perceived imminent shifting of neighborhood racial composition, and middle-class flight, by both white and black residents, based on changes in the social and income composition of neighborhoods (Harell 1994). As such, this theory places emphasis on social and ethnic preferences as primary motivators in household residential location decisions (Varady 1983).

Leven et al. (1976) reach a similar conclusion with regard to the role of arbitrage, but also place significant weight on household preferences in the housing bundle. These preferences concern not only the physical characteristics of housing but also many other attributes, i.e., green areas, racial and/or ethnic composition, school quality, etc., that have greater impact in setting housing values than such physical traits. Leven et al. also note that passive filtering in postwar North America has been closely associated with declining levels of neighborhood income and racial change and that the neighborhood life cycle ends in abandonment and demolition. As a consequence successive households will suffer individual loss, and the eventual neighborhood depletion to urban 
wasteland produces general social negative externalities (Leven et al. 1976).

The third neighborhood change model stresses neighborhood structure and composition. As noted by Harrell and Geuvis (1994), theorists under this rubric emphasize the differential ability of social classes to compete for residential location within an urban area. This model follows the ecological discourse of the Chicago School of Sociology (Park et al. 1925, Harris and Ullman 1945). It places more weight on the bundle of location features that contribute to housing quality. Combinations of attributes such as transportation access, environmental amenities such as green areas, physical characteristics of the housing stock and other location attributes are part of the housing bundle that is valued by renters and home purchasers (Harrell and Geuvis 1994).

Socioeconomic and housing characteristic trends identified for the three neighborhoods under study indicate that the two lowerincome neighborhoods of Puerto Nuevo and Caparra Terrace are experiencing decline. Their trends correspond both to the neighborhood decline cycle model as well as to the arbitrage model. Key tendencies that confirm this hypothesis include increase in rental units (Fig. 7), alterations to existing structures as reflected in an increase in multifamily units (Fig. 2), increase in density (Fig. 1), higher and increasing poverty rates (Figs. 3, 4, 5), declining structure values relative to the larger metropolitan area (Fig. 6), and increase in racial and ethnic diversity (Figs. 11, 12, 13).

Because these processes are accompanied by an increase in housing units and increase in density we believe that neighborhood life cycle and arbitrage mechanisms play a central role in explaining Puerto Nuevo's and Caparra Terrace's higher rate of green area and green cover losses. On the other hand, because University Gardens reports a more stable socioeconomic, green area, and green cover scenario, the neighborhood structure and composition model might best explain its distinct evolution as compared with the lower income neighborhoods.

Nevertheless, the increase in housing units and density associated to neighborhood decay processes in Puerto Nuevo and Caparra Terrace does not explain the totality of green area loss in these neighborhoods. Additional factors identified in this study that contribute to a higher rate of green area and green cover losses in these two neighborhoods are: substantial increases in automobile ownership, weak governance of the built environment, and distinct design characteristics.

The notable increase in private automobile ownership in both lower income communities plays an important role in explaining their higher rate of green area and green cover losses (Fig. 10). A significant portion of street planting strips, front and side yards have succumbed to informal paving and new carports for automobile parking (Figs. 2, 10). Also, in the case of Puerto Nuevo, the original width of internal streets did not allow for parallel parking without sacrificing bidirectional traffic flow. This design characteristic propelled the invasion of the great majority of sidewalks, planting strips, and front patios in Puerto Nuevo (Appendix 7).

The instances of private covenants and patio zoning violations in both neighborhoods is vast and reflects on the weak governance of the built environment at both the community and governmental levels. The increase in housing demand and density could have been accommodated in vertical expansions, allowed under the original and present ordinances, while preserving the original yard areas. Likewise, the increases in parking demand, under effective governmental urban planning could have been accommodated in accessible communal facilities thus preserving the limited green areas in these communities. Differential treatment among low-income and high-income communities by public institutions with regard to the enforcement of land-use and building regulations could be occurring as well as different levels of human capital and political clout that could effect stricter compliance of ordinances.

Fig. 11. Percent black.

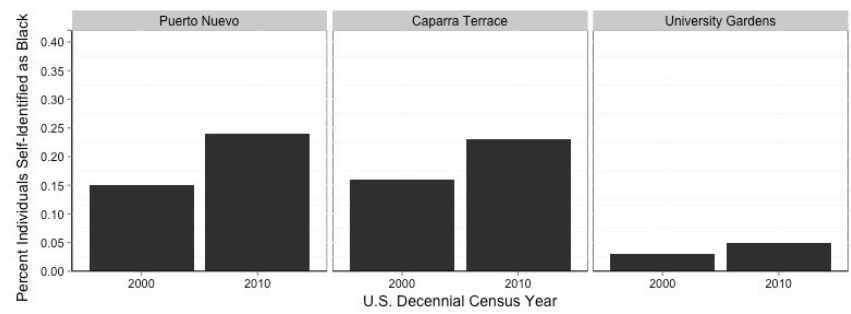

Fig. 12. Percent foreign born.

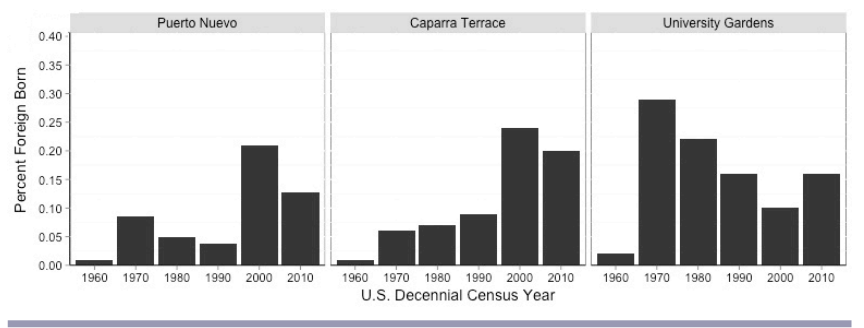

Fig. 13. Percent nonwhite.

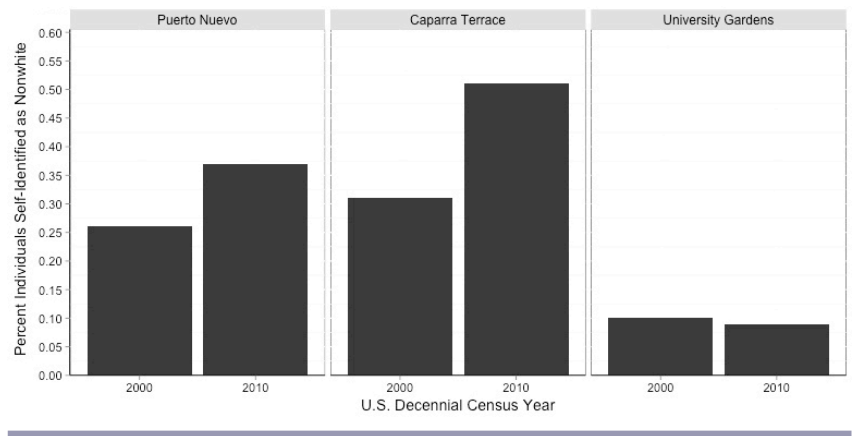

Design characteristics of these two lower income communities, such as the absence of carports and parking spaces in their original 
schemes, narrower than standard streets, and smaller lots can be considered as pre-existing characteristics conditioned by the market for which they were originally developed and real-estate economics. As such these communities were more vulnerable to suffer green area losses in the event of increases in demand for housing and parking spaces, as conditioned by their socioeconomic rank. Finally, architectural and functional alterations, such as balconies, larger kitchens, larger bedrooms and the like occur in all three neighborhoods and contribute in some part to the loss of green areas.

Therefore, a variety of factors interplay in rendering higher rates of green area and green cover losses in the lower income communities of Puerto Nuevo and Caparra Terrace. Neighborhood decay processes, together with increased demand for parking, weak governance of the built environment, inherent design characteristics, among others explains a large portion of green area and green cover losses. The data, factors, and trends identified in this research render these lower income neighborhoods more vulnerable to green area loss and green cover loss and more vulnerable to the concomitant diminishment of environmental services associated with suburban green areas.

The results and the complexity in factors and drivers that create green area and green cover losses raise issues that go beyond the original environmental concerns of this study and bring forth issues of socioeconomic inequalities and environmental justice. Neighborhood decline in lower income communities within weak governance scenarios appears to be concomitant with local and large-scale environmental degradation as manifest in greater green area and green cover losses. Given that this deterioration process has been observed in other suburban neighborhoods of similar age and rank on the island, a larger sampling of neighborhoods is warranted to conduct statistically significant studies that could help gauge the magnitude of the problem, test hypotheses, and inform future policies.

The accumulated loss of green area and green cover represents a diminishment of environmental services (Tratalos et al. 2007, Di Giulio et al. 2009, James et al. 2009, Pickett et al. 2011, Ward Thompson et al. 2012), a reduction of amenities, and potentially a reduction in value of the housing bundle, thus affecting future structure values more so in Puerto Nuevo and Caparra Terrace than in University Gardens. Additionally, increased impermeability of ground cover implies disruption of ground water cycles, increase of storm water runoff to the governing water body (Río Piedras River), increased vulnerability to flooding in downstream communities, and increase in the amount of sediments and urban contaminants downstream (Picket et al. 2011). Reduction of green area also implies a diminishment in biodiversity and in the psychological and health benefits to residents and adjacent communities (Di Giulio et al. 2009, James et al. 2009, Picket et al. 2011, Ward Thompson 2012). Further, a reduction in the potential for carbon absorption is linked to a reduction in green area and green cover (Tratalos et al. 2007).

The complexity and variety of exogenous and endogenous factors that have been identified in this study as having an effect on innerring suburbs' private and public green areas reveals dynamic and spatially differentiated, concomitant processes. National- and metropolitan-scale economic growth and development propels residential to commercial land-use conversions along peripheral arterial avenues and internal collector streets (Ramos 2008). The simultaneous aging of housing stock and socioeconomic change associated with neighborhood decay, via arbitrage/filtrationsuccession mechanisms, drive increments in density, rentals, and housing units at the residential core of the two lower income neighborhoods. In the upper income neighborhood most of the increment in gross density and housing units was accommodated in multistory condominium typologies with minimal impact on green areas and imperceptible to the overall neighborhood suburban character.

In addition a progressive shift in transportation mode from bus transit to massive individual car ownership in the two lower income neighborhoods represents an additional driver of change. Because of specific physical-spatial limitations in the two lower income neighborhoods the increment of automobile ownership results in higher diminishment of private and public green areas and green cover. Finally, cultural preferences and unforeseen resident spatial needs produce smaller aggregate footprint expansions that contribute to overall green area loss in time. All these processes (outlined in Appendix 8) occurred despite clear and specific cultural arrangements (zoning and private covenants) that sought to maintain open green areas in private and public lands and the general suburban character and value of the neighborhoods.

Based on the data, trends, and analysis conducted in this exploratory research, we posit the following hypotheses:

1. Inner-ring suburban neighborhoods undergoing processes of socioeconomic decline and built-environment transformations within a context of weak governance are more likely to experience greater losses of green area and green cover in time than neighborhoods that experience more stable socioeconomic trajectories.

2. The continuous loss of green area and green cover in innerring suburbs reduces the overall value of the housing bundle and thus becomes a reinforcing positive feedback into the neighborhood decay process.

3. Lower income inner-ring suburbs are more vulnerable to green area and green cover loss than higher income innerring suburbs because differential government enforcement of built-environment ordinances, human capital, and political clout exists among the social groups as well as distinct design characteristics that reduce the resilience of lower income inner-ring suburbs to adapt to changes in housing and parking demands.

\section{POLICY IMPLICATIONS}

Because of the negative environmental, social, and economic consequences associated with green area and green cover losses as well as with neighborhood decay processes in Puerto Nuevo and Caparra Terrace recommendations for short-term and longterm actions need not wait for hypotheses testing. The consensus among most neighborhood change scholars with regard to the ultimate urban blight outcome of unattended neighborhoods in distress should call to attention government action and planning for positive social change.

Enforcement of patio ordinances together with promotion of vertical construction to accommodate the increase in housing 
demand in San Juan's inner-ring suburbs should take place. Reestablishment of communal and private green areas and tree planting should be promoted where possible. Raising awareness of the negative consequences of green area and green cover losses in the local communities should also be part of an integrated effort in inner-ring suburbs of San Juan City as well as promoting residents' and owners' active participation in the governance of their environments. Likewise, implementing neighborhood scale parking facilities that can accommodate the increasing rate of automobile ownership while minimizing green area impacts is another key aspect of a sustainable adaptation strategy. As such, urban planning, urban design, and architectural design are key aspects in this endeavor.

Unfortunately the massive loss of private and public green areas that Puerto Nuevo and Caparra Terrace experienced in the last over-50 years requires a different type of strategy within a longterm framework if substantial green areas are to be recuperated. Viewed from a system dynamics lens (Walker et al. 2004), the social-economical-environmental trajectories of the two lower income neighborhoods indicate a path to undesirable state of decline that warrants intervention through adaptive governance. In the case of Puerto Nuevo and Caparra Terrace the goals would be to diminish the resilience of the present system and allow for transformability into a more sustainable state. In the case of University Gardens the contrary would be true; the goal would be to increment its resilience through adaptive management so as to prevent it from entering a cycle of decay and substantial green area loss, such as the one described for Puerto Nuevo and Caparra Terrace.

From a public policy standpoint, the inner-ring neighborhoods undergoing decline need to be the focus of government in a proactive and comprehensive manner because they represent substantial areas of the built environment. Their strategic central location within the San Juan Metropolitan Area, their adjacency to the main arterial avenues and transport networks, their proximity to central commercial/work/institutional destinations, their inherent and latent urban design attributes, and the current decelerating real estate valuation suggest potential and opportunity for more sustainable human settlements through simultaneous physical redevelopment and socioeconomic revitalization in which green areas and their innate environmental services can be recuperated.

Because redevelopment economics maintain higher intensity developments (Goodall 1972), a higher density scenario informed by ecological urban design could integrate and recuperate lost green areas within each new residential development as a regulated and required item. Ramos's (2008) research with regard to this topic has explored specific architectural typologies integrated to neighborhood-scale urban restructuring schemes for advancing more sustainable and environmentally conscious designs in deteriorating inner-ring neighborhoods. A study conducted for one of the 11 neighborhoods in Puerto Nuevo reported economic feasibility of higher density residential redevelopment together with the creation of substantial new permeable green areas $(35 \%$ of total neighborhood land at 180 housing units/ha residential density) if properly subsidized by the public sector and planned for low-income and middle-income markets, which is the largest housing market in San Juan (90\%) and currently unattended.
The competing needs for land by higher density uses and by green areas in urban contexts, both associated with current policies and paradigms geared to sustainable urban redevelopment (Goodall 1972, Farr 2008, Ramos 2008, Dunham-Jones and Williamson 2011) requires a trade-off analysis in which a thorough account of costs and benefits is warranted. As such urban ecological design is foreseen as instrumental in this process of adaptive governance in which architects, urban designers, planners, and scientists work from a common transdisciplinary framework.

Responses to this article can be read online at: http://www.ecologyandsociety.org/issues/responses. php/6219

\section{Acknowledgments:}

NSF IGERT Grant \#0801577 supported this work. This paper forms part of a larger ongoing, multidisciplinary and interdisciplinary research effort that seeks to understand long-term social-ecological urban dynamics within a densely populated tropical river watershed: "San Juan ULTRA-Exploratory," which is funded by the National Science Foundation and the International Institute for Tropical Forestry of the U.S. Forest Service. Special thanks to Ariel Lugo from the U.S. Forest Service for his comments and reviews. Thanks also to Dr. Jeffrey Brown and Dr. Michael Duncan from The Florida State University, Department of Urban and Regional Planning for their comments and suggestions.

\section{LITERATURE CITED}

Aspinall, R. 2006. Editorial. Journal of Land Use Science 1:1-4.

Aspinall, R., and M. Hill, editors. 2008. Land use change: science, policy, and management. CRC Press, Taylor and Francis Group, Boca Raton, Florida, USA.

Boyden, S. 1992. Bio-history: the interplay between human society and the biosphere - past and present. Parthenon, Park Ridge, New Jersey, USA.

Di Giulio, M., R. Holderegger, and S. Tobias. 2009. Effects of habitat and landscape fragmentation on humans and biodiversity in densely populated landscapes. Journal of Environmental Management 90:2959-2968. http://dx.doi.org/10.1016/j. jenvman.2009.05.002

Downs, A. 1981. Neighborhoods and urban development. Brookings Institution Press, Washington, D.C., USA.

Dunham-Jones, E., and J. Williamson. 2011, Retrofitting suburbia: urban design solutions for redesigning suburbs. First edition. John Wiley \& Sons, Hoboken, New Jersey, USA.

El Mundo. 1948a. El caserío Puerto Nuevo de San Juan desde el aire. 22 August.

El Mundo. 1948b. Exhiben película de Puerto Nuevo: se estima que la verán 13,000,000 en EE.UU. 23 August.

Farr, D. 2008. Sustainable urbanism: urban design with nature. First edition. John Wiley \& Sons, Hoboken, New Jersey, USA. 
Goodall, B. 1972. The economics of urban areas. First edition. Pergamon, Oxford, UK. http://dx.doi.org/10.1016/ B978-0-08-016892-0.50002-8

Hanlon, B. 2009. Once the American dream: inner ring suburbs of the metropolitan United States. Temple University Press, Philadelphia, Pennsylvania, USA.

Harrell, A., and C. Geuvis. 1994. Predicting neighborhood risk of crime. Report to the National Institute of Justice. The Urban Institute, Washington, D.C., USA.

Harris, C., and E. Ullman. 1945. The nature of cities. Annals of the American Academy of Political and Social Science 242(1):7-17. http://dx.doi.org/10.1177/000271624524200103

Hoover, E., and R. Vernon. 1959. Anatomy of a metropolis: the changing distribution of people and jobs within the New York Metropolitan Region. Harvard University Press, Cambridge, Massachusetts, USA.

James, P., K. Tzoulas, M. D. Adams, A. Barber, J. Box, J. Breuste, T. Elmqvist, M. Frith, C. Gordon, K. L. Greening, et al. 2009. Towards an integrated understanding of green space in the European built environment. Urban Forestry \& Urban Greening 8(2):65-75. http://dx.doi.org/10.1016/j.ufug.2009.02.001

Kinzig, A. P., P. Warren, C. Martin, D. Hope, and M. Katti. 2005. The effects of human socioeconomic status and cultural characteristics on urban patterns of biodiversity. Ecology and Society 10(1): 23. [online] URL: http://www.ecologyandsociety. org/vol10/iss1/art23/

Lang, J.1987. Creating architectural theory: the role of the behavioral sciences in environmental design. Van Norstrand Reinhold, New York, New York, USA.

Lee, S. 2005. Metropolitan growth patterns' impact on intraregional spatial differentiation and inner-ring suburban decline: insights for smart growth. Dissertation, Georgia Institute of Technology, Atlanta, Georgia, USA.

Leven, C., J. T. Little, H. O. Nourse, and R. B. Reid. 1976. Neighborhood change: lessons in the dynamics of urban decay. Praeger, New York, New York, USA.

Little, J. 1977. The dynamics of neighborhood change. Pages 63-72 in D. Phores, editor. A decent home and environment: housing urban America. Ballinger, Cambridge, Massachusetts, USA.

Lowry, I. 1960. Filtering and housing standards: a conceptual analysis. Land Economics 36:362-370. http://dx.doi.org/10.2307/3144430

Lozano, E. 1990. Community design and the culture of cities: the crossroad and the wall. Cambridge University Press, Cambridge, UK.

Metzger, J. T. 2000. Planned abandonment: the neighborhood life-cycle theory and national urban policy. Housing Policy Debate 11(1):7-40. http://dx.doi.org/10.1080/10511482.2000.9521359

Park, R., E. Burgess, and R. McKenzie. 1925. The city. University of Chicago Press, Chicago, Illinois, USA.

Pickett, S. T. A., M. L. Cadenasso, J. M. Grove, C. G. Boone, P. M. Groffman, E. Irwin, S. S. Kaushal, V. Marshall, B. P. McGrath, C. H. Nilon, et al. 2011. Urban ecological systems: scientific foundations and a decade of progress. Journal of Environmental Management 92(3):331-362. http://dx.doi.org/10.1016/j. jenvman.2010.08.022

Ramos, L. E. 2008. Towards an urban and sustainable Puerto Nuevo: a green redevelopment of the first suburbs in San Juan, Puerto Rico. Thesis, Graduate School of Planning, University of Puerto Rico, Río Piedras, Puerto Rico, USA.

Ramos, L. E. 2012. Planificación e Implantación de Utopías Suburbanas en San Juan de Puerto Rico. Patrimonio 2:52-61.

Rodríguez-Meléndez, Y. N. 2012. Relevancia de la figura de servidumbre en equidad en el desarrollo y planificación del Puerto Rico actual: El caso de Puerto Nuevo. University of Puerto Rico Business Law Journal 3(1):101-110.

Schwab, W. 1987. The predictive value of three ecological models: a test of the life-cycle, arbitrage, and composition models of neighborhood change. Urban Affairs Review 23:295-308. http:// dx.doi.org/10.1177/004208168702300207

Sepúlveda, A. 2003. Viejos Cañaverales, Casas Nuevas: Muñoz versus el Síndrome Long. Pages 167-207 in F. Pico, editor. Luis Muñoz Marín, Perfiles de su Gobernación, 1948-1964. Fundación Luis Muñoz Marín, San Juan, Puerto Rico, USA.

Smith, N. 1979. Toward a theory of gentrification: a back to the city movement by capital, not people. Journal of the American Planning Association 45(4):538-548. http://dx.doi. org/10.1080/01944367908977002

Tratalos, J., R. Fuller, P. Warren, R. Davies, and K. Gaston. 2007. Urban form, biodiversity potential and ecosystem services. Landscape and Urban Planning 83(4):308-317. http://dx.doi. org/10.1016/j.landurbplan.2007.05.003

U.S. Census Bureau. 2010. Census 2010. U.S. Census Bureau, Washington, D.C., USA. [online] URL: http://www.census. gov/2010census/

Varady, D. 1983. Determinants of residential mobility decisions: the role of government services in relation to other factors. Journal of American Planning Association 49(2):184-199. http://dx.doi. org/10.1080/01944368308977063

Walker, B., C. S. Holling, S. R. Carpenter, and A. Kinzig. 2004. Resilience, adaptability and transformability in social-ecological systems. Ecology and Society 9(2): 5. URL: http://www. ecologyandsociety.org/vol9/iss2/art5

Ward Thompson, C., J. Roe, P. Aspinall, R. Mitchell, A. Clow, and D. Miller. 2012. More green space is linked to less stress in deprived communities: evidence from salivary cortisol patterns. Landscape and Urban Planning 105(2012):221-229. http://dx.doi. org/10.1016/j.landurbplan.2011.12.015 


\section{Appendix 1}

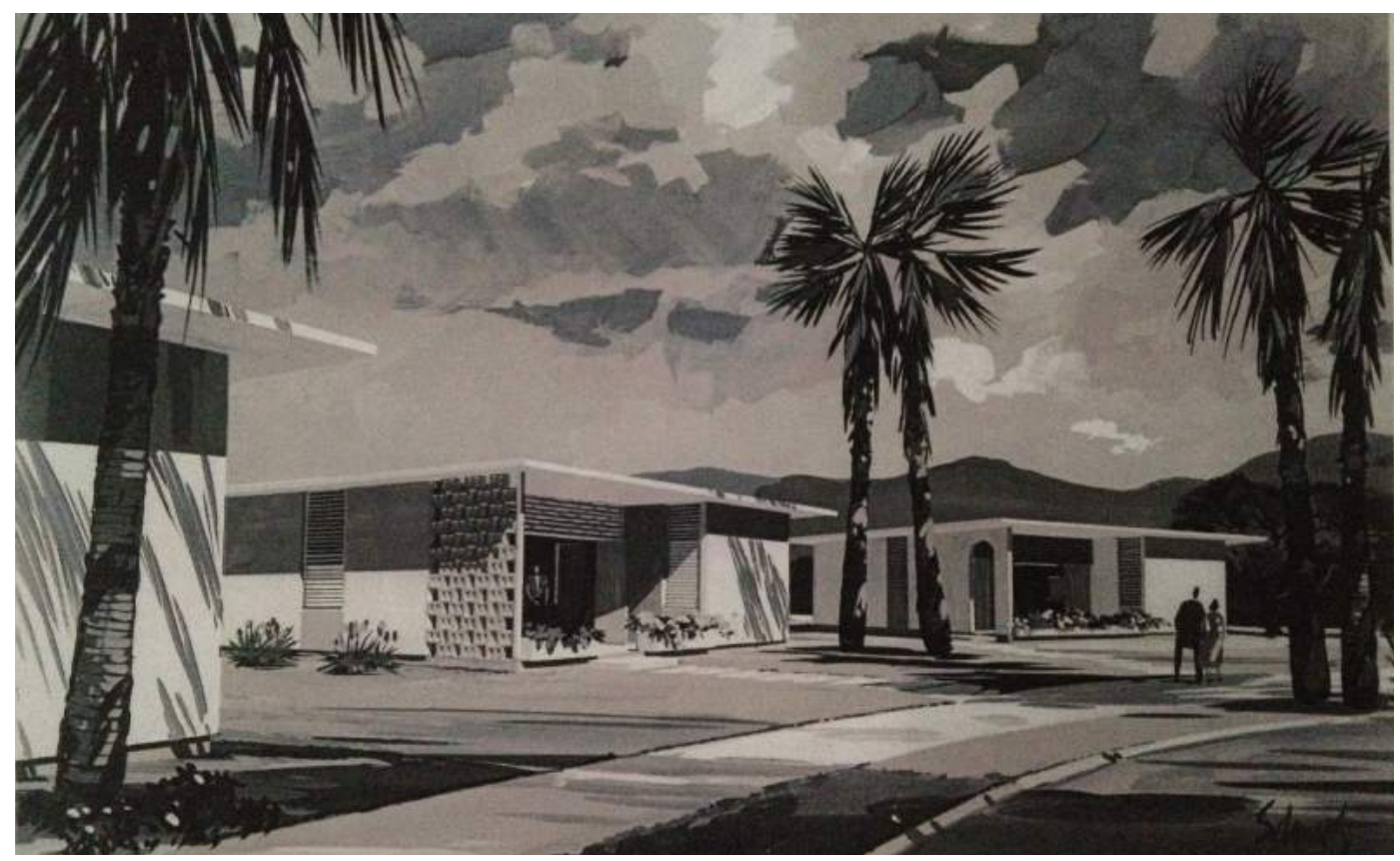

(Above) Watercolor rendering of two architectural models for the single-family home "Tradewinds" in Villas Las Lomas development, which is part of Caparra Terrace neighborhood census tract 83.00; Courtesy of Rockefeller Archive Center $\odot$, watercolor, AIA Photo Collection 1027, www.rockarch.org. Notice amount and importance of public and private green areas in defining the overall suburban landscape, aesthetic experience, and marketing value. Boxy one-storied reinforced-concrete single-family homes are the predominant type in Puerto Rico's suburban landscape.

(Below) Streetscape photograph of the same development at the intersection of $18 \mathrm{SW}$ and 21SW streets, year 2013. Notice alterations to original structures: carport additions, balconies, second floor additions (mostly for rent), conversion of front and side yards to parking surface, and elimination of private and public green areas (street planting strip). Mature trees in the background occur in publicly owned creek right-of way. The original suburban landscape of this part of San Juan City has evolved into a denser, yet less populated residential area at the expense of substantial green areas.

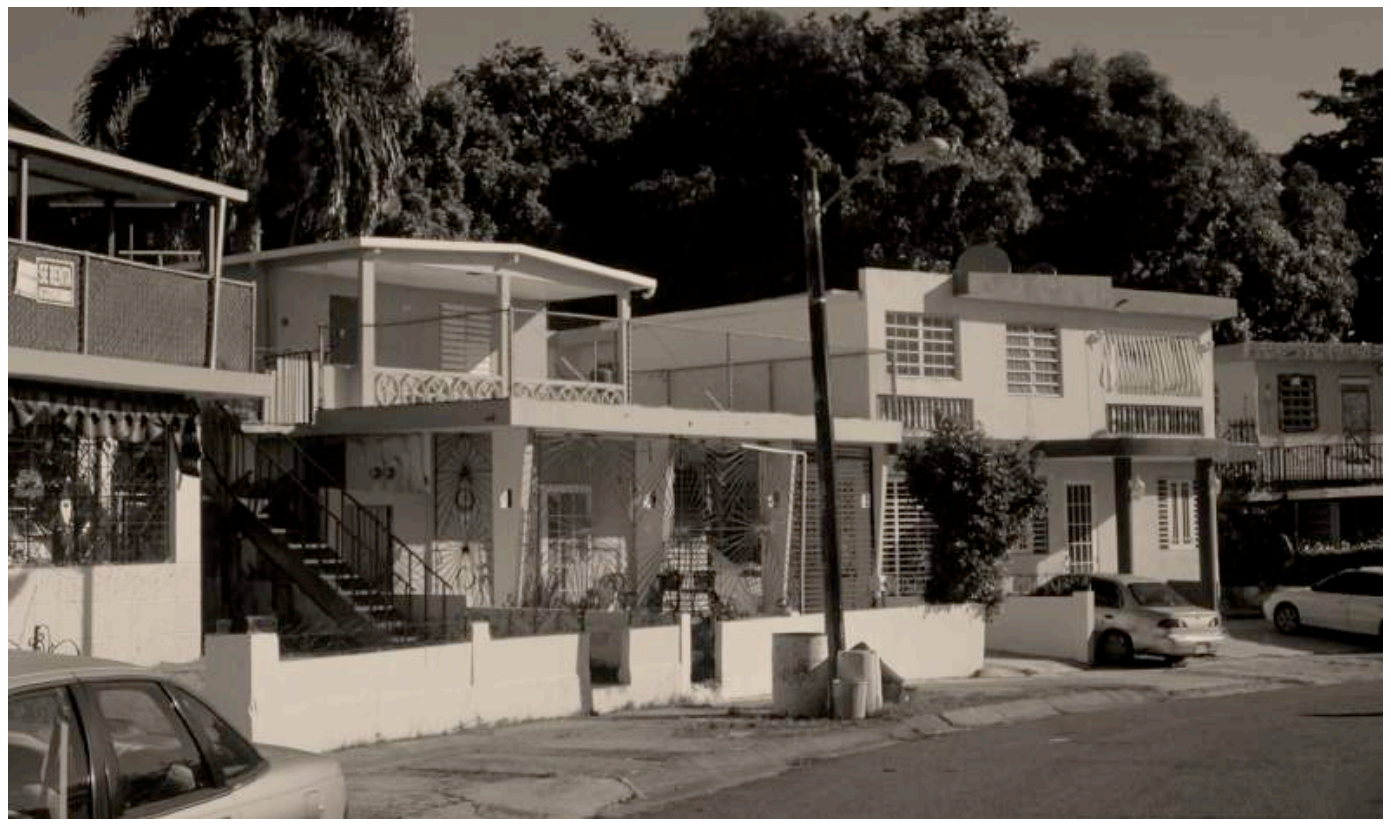


Appendix 2

Green AREA Loss/Gain

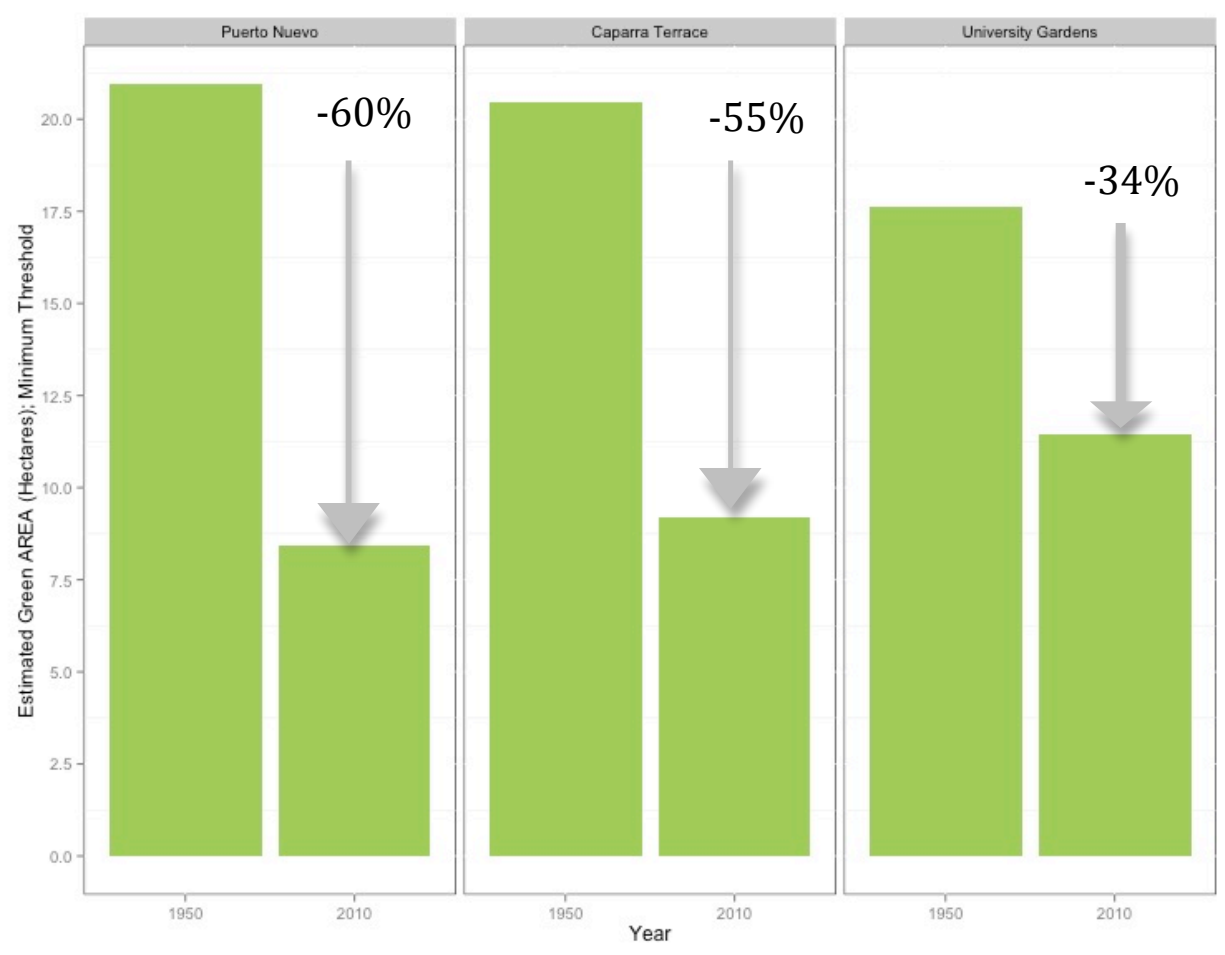

Green COVER Loss/Gain

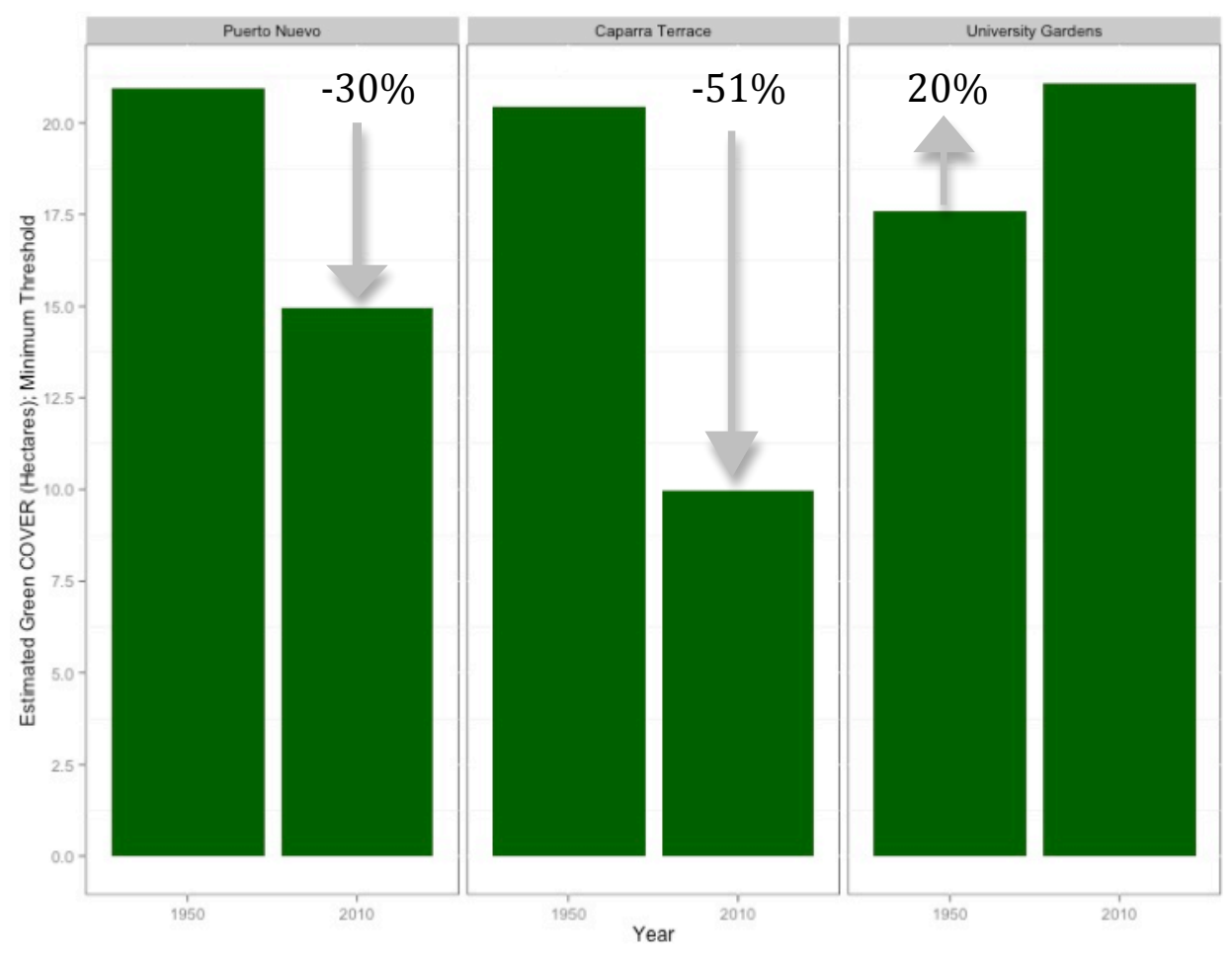


Appendix 3

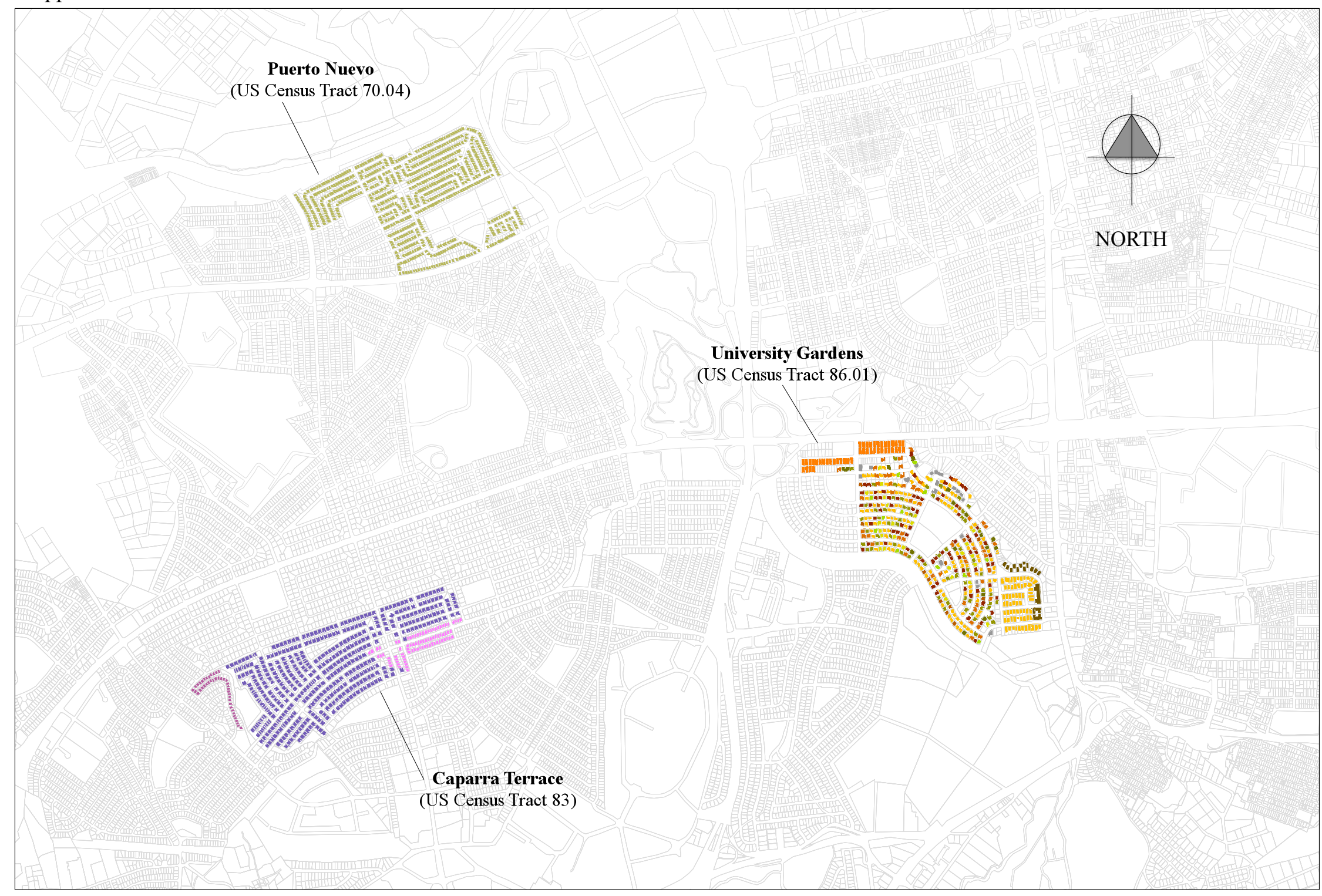




\section{Appendix 4}

Puerto Nuevo

1948 - 2010

Increase in Building Footprint

Private Green Area Loss

\begin{tabular}{|l|l|}
\hline $209 \%$ & $\mathbf{1 0 . 4 5}$ ha \\
\hline
\end{tabular}
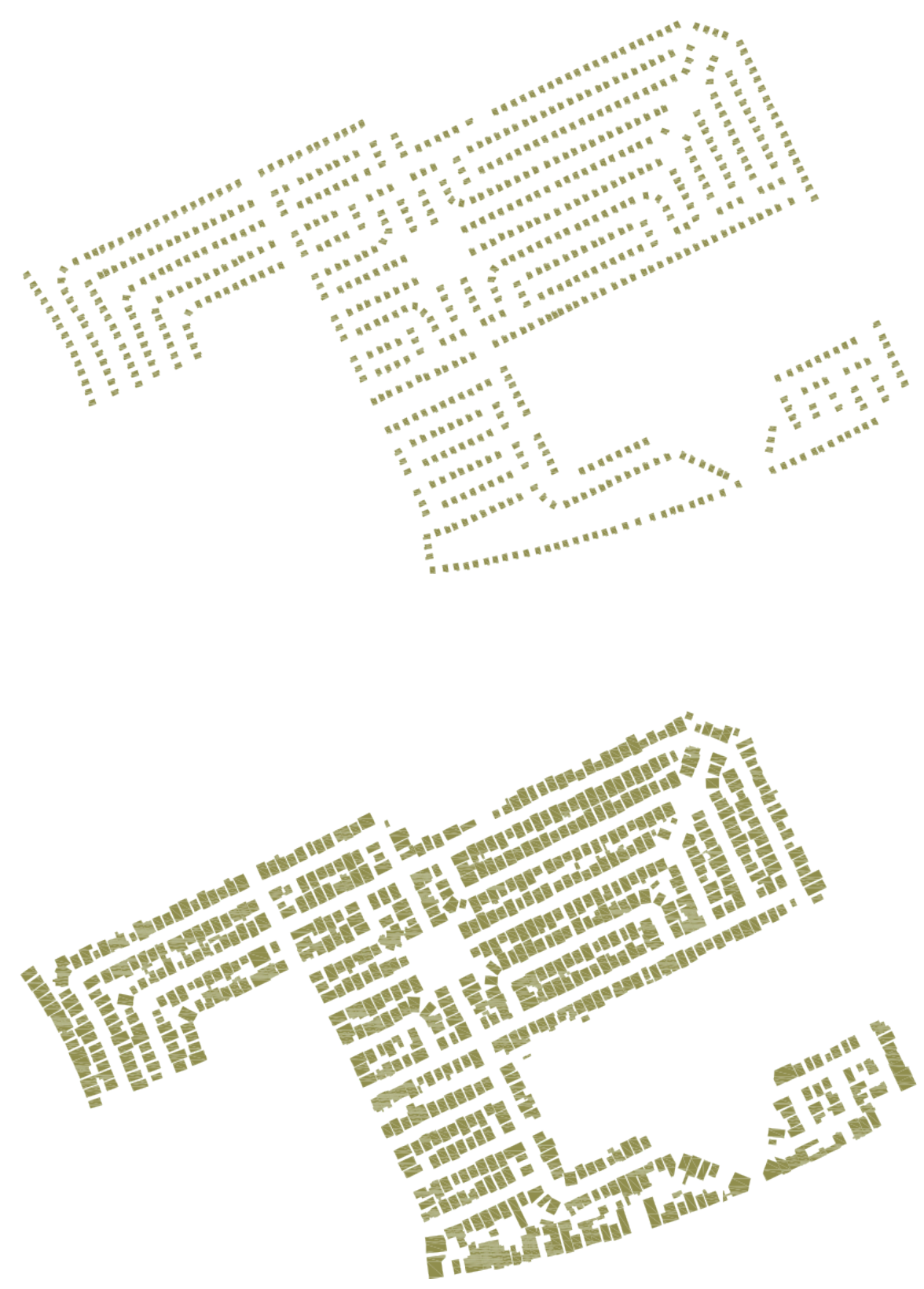


\section{Appendix 5}

\section{Caparra Terrace}

$1956-2010$

Increase in Building Footprint Private Green Area Loss

\begin{tabular}{|c|c|}
\hline $135 \%$ & $\mathbf{1 0 . 2 6} \mathbf{h a}$ \\
\hline
\end{tabular}
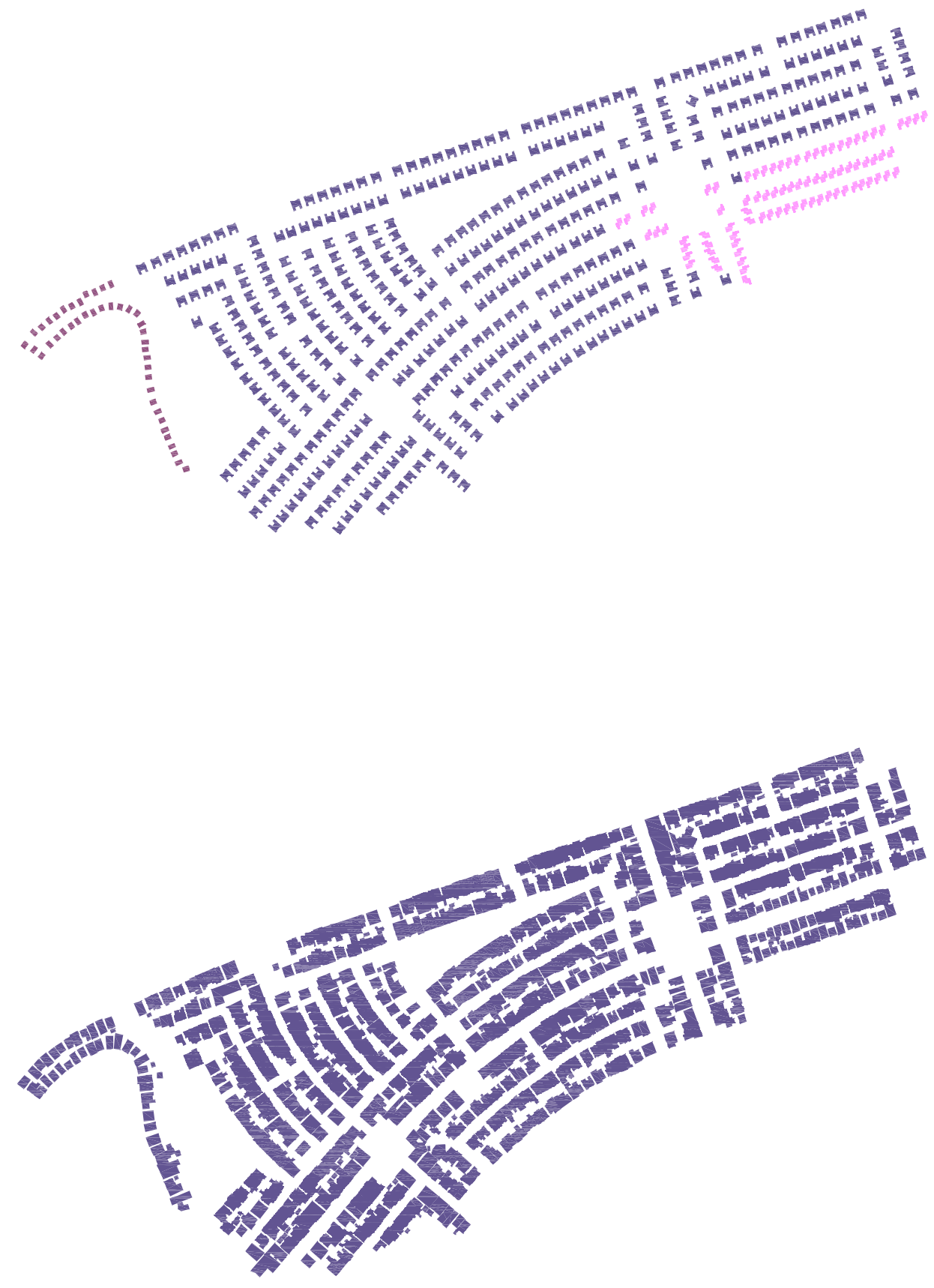


\section{Appendix 6}

\section{University Gardens}

1959 - 2010
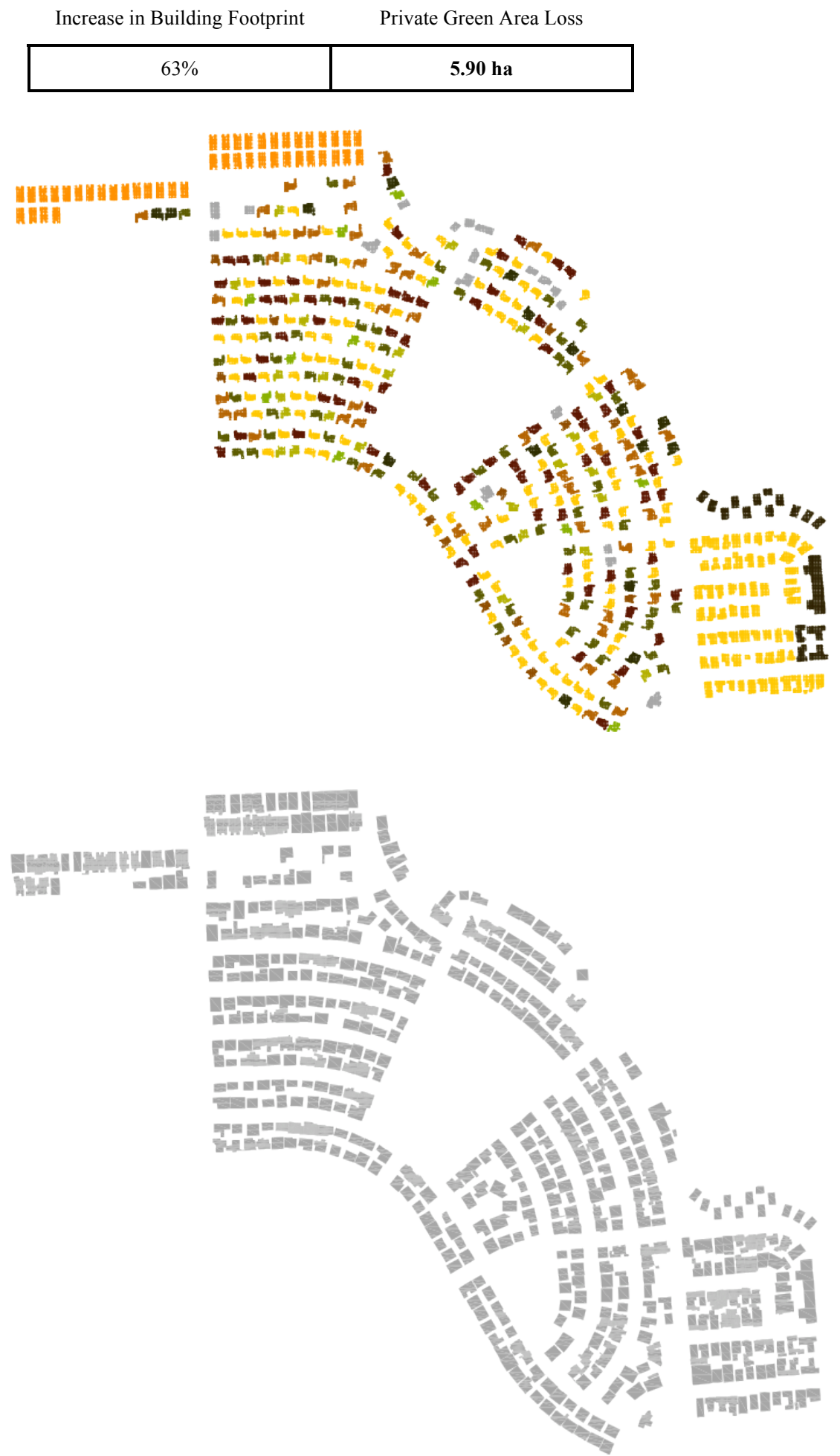


\section{Appendix 7}

Street Planting-Strip Loss
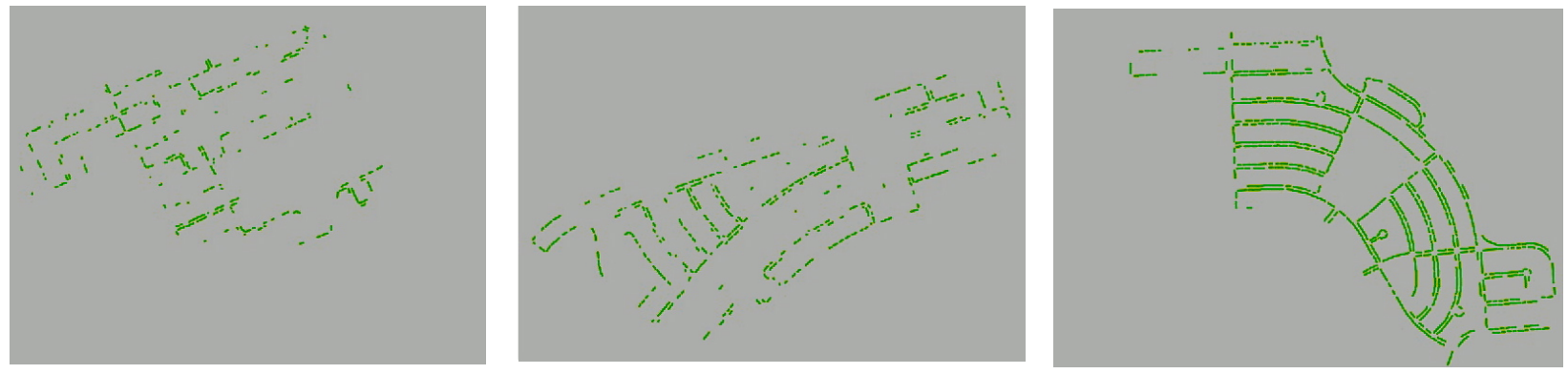

Puerto Nuevo

low-income

1948-2008

2.06 ha

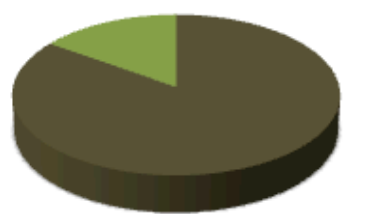

\section{Caparra Terrace}

low-income

1956-2008

0.98 ha

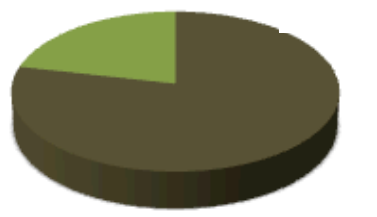

- STREET PLANTING STRIP

LOST

- remaining planting STRIP ESTIMATE
University Gardens

high-income 1960s-2008

0.26 ha

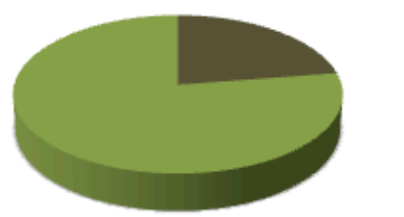




\section{Appendix 8}

\section{Low-Income Inner-ring Suburbs Green/Gray Area Dynamics Model}

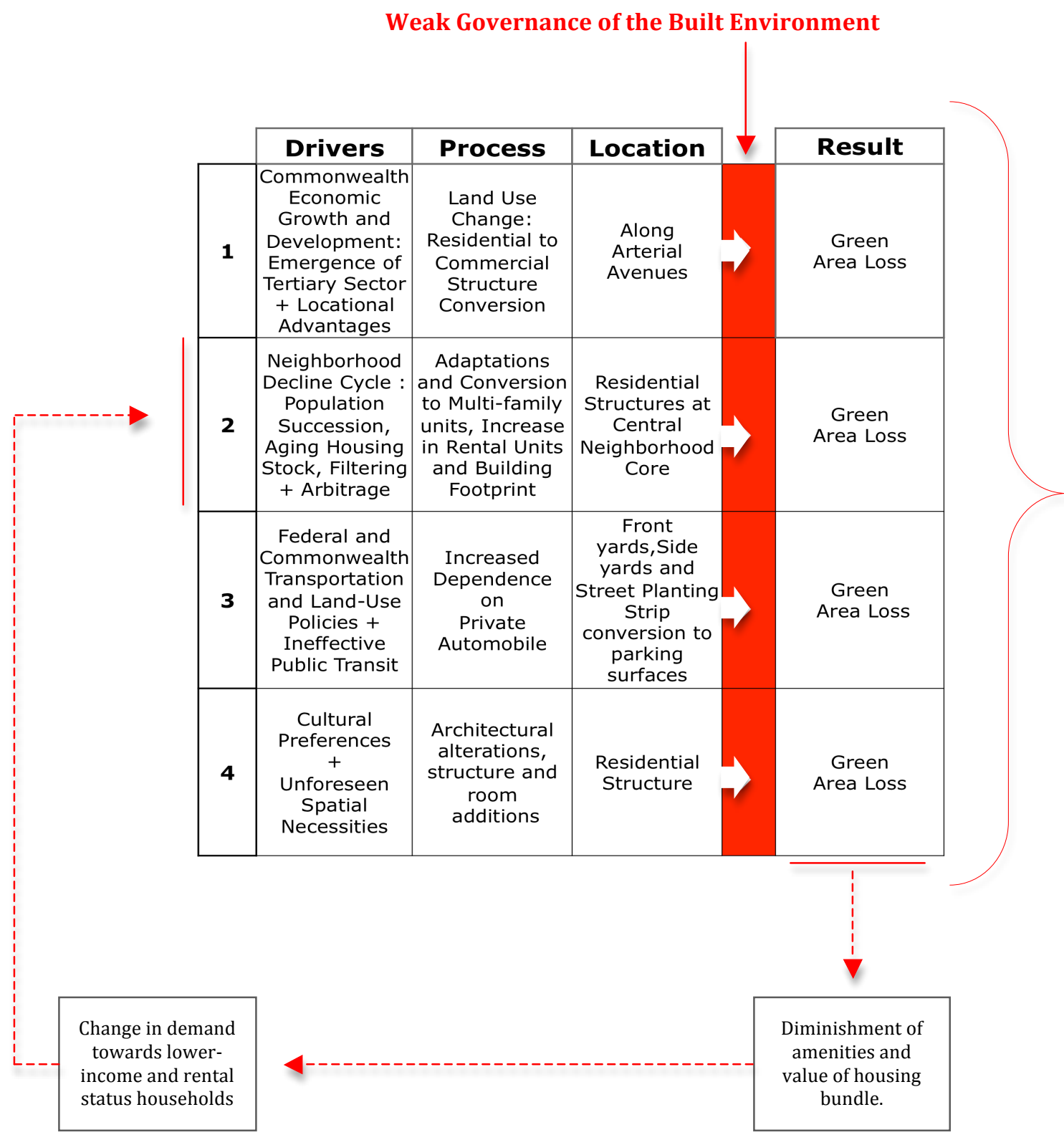

